Gaule, Über d. Druckverhältnisse im Innern d. Herzens. Pflügers Arch. Bd. 17. 12. $\mathrm{H}$ o f $\mathrm{m}$ a $\mathrm{n}, \mathrm{K}$ patolog. anatomii sierdea pri sklerosie arterii. 1886. - 13. Iw an ow sky, a) $\mathrm{K}$ patolog. anatom. sypnowo tifa. Zurnal dla normalnoj i patolog. gistolog. Rudniewa. 1876. b) Uczebnik patolog. anatom. 1885 u. 1886. - 14. Ka cow s kj, K woprosu ob izmienienjach nierw. uzlow sierdea pri ostrych otraw. mineral. kislotami. Diss. 1894. 15. Koplewskij, Ob anatomi izmienienjach uzlow sierdea pri niekotorych patolog. proces. w sierdiecznoj mysrce. Pietierburg. Diss. 1881. - 16. K o r ole w, Ob izmienienjach nierw. uzlow sierdca bluždajuszczawo nierwa $\mathrm{i}$ prodolgowat. mozga pri mechanicz. zatrud. dychanja. Diss. 1899. - 17. K ul b in, Alkogolizm. K woprosu o wlijanii chronicz, otraw. etilowym alkogol. i siwusz. maslom na žiwotnych. Pietierburg. Diss. 1895. 18. Kuzniecow, Ob izmienienjach sierdiecznych uzlow pri ostrych $i$ podostrych endokarditach. Pietierburg. Diss. 1892. - 19. Melnik ow-Raswedenkow, Histolog. Untersuch. über $d$. elastische Gewebe in normal. $\mathfrak{u}$. in patholog. Veränderungen. Zieglers Beiträge Bd. 26. - 20. Marin e s c o, Zentralblatt f. allg. Patholog. u. patholog. Anatomie. 1899. Nr. 19. 20. 21. 22. - 21. Natan s on, Patolog. anatom. izmien. awtomat. nierw. uzlow sierdca pri wozwrat. goriaczkie. Pietierburg. Diss. $1896 .-22.0 \mathrm{kmianskij}$, Patolog. anatom. izmienienja nierw. uzlow sierdca pri ostrom alkogolizmie u žiwotnych. Pietierburg. 1901. - 23. Pug nat, Des modifications histolog. d. cellnles nerveuses dans l'état de faligue. Ac. des sciences. Novembre 1897. - 24. Qu ervain, Virchows Arch. Bd. 133, S. 48 und Virchows Arch. Bd. 107. - 25. Rosenbach, 0 wlijanii golodanja na nierw. centry. Diss. 1883. - 26. Straussler, Jahrbücher f. Psychiatrie u. Neurologie. Bd. 21. Hft. 1, 2. - 27. Su chanow, Kratkij oczerk sowremiennawo uczenja o tonczajsrem strojenii nerwnoj kletki Zurnal. Korsakowa. 1901. S. 14. - 28. Tr z e bi n sk i, Virchows Arch. Bd. 197, S. 120. - 29. W e in ri c h, Über Nerven u. Ganglien im Säugetierherzen. Inaugur.-Diss. 1888. - 30. W i n o g rad ow, Izmienien. sierdiecz. azlow of chloroforma. Wracz. 1884. Nr. 37-40. - 31. D e r s., Izmien. sierdiecz. nierw. uzlow pri krupoznoj pnewmon. Dniew. Moskow. Pietierburg. Miedicin. obszczestwa. 1886. 32. D ers., Ostroje otraw. kokain. co smiert. ischodom. Feženied. klinicz. gazeta. 1889.

\title{
XVIII.
}

\section{Über die Frage der infektiösen Thrombose.}

(Aus dem Pathologisehen Institut zu Bonn a. Rh.)

Von

Dr. med. C. N a g o y a

ans Japan.

I. Ein leitung.

Seit Virchow ${ }^{1}$, der sich um die Erforschung der Thrombose große Verdienste erwarb und die bekannte mechanische Theorie begründete, wurde dasselbe Problem von vielen Autoren, $\mathrm{B}$ i z z o z e r $0^{2}$, $\mathrm{H}$ a n a $\mathrm{u}^{3}$, L 0 wit ${ }^{4}$, Arnold ${ }^{5}$, Eberth und Schimmelbuseh ${ }^{6}, Z_{a h n}{ }^{7}$, Brücke ${ }^{8}, \mathrm{Cohnheim}^{9}$, Baumgarten ${ }^{10}$, v. Recklinghausen ${ }^{11}, A s c h$ of $f^{12}$ und $R i b$ b e r t ${ }^{14}$ eifrig erforscht. Sie untersuchten vom mikroskopischen und experimentellen Standpunkte aus und sind durch ihre Untersuchungen zu verschiedenen Ansichten gekommen (die mechanische, chemische, toxisch-infektiöse Theorie usw.). 
Im Jahre 1909 hat $\mathrm{Kr}$ et $\mathrm{z}^{15}$ ) über die Thrombose in der „Med. Klin." berichtet und war-der Meinung, daß das infektiöse Moment anscheinend immer die letzte Ursache des Entstehens der Thrombose im venösen großen Kreislauf und auch Bedingung des Entstehens der Lungenembolie ist. Er konnte in den Fällen von Venenklappenthrombose, wie sie gerade im Gebiete dex Vena femoralis am häufigsten vorkommen, keine entzündliche Wandveränderung entdecken und glaubte, diese Fälle durch eine Blutinfektion erklären zu können. Die Blutinfektion ist es, welche die Gerinnung des Blutes innerhalb der GefäBe bedingt. Dabei stützte K r e t z sich auf die Experimente von $\mathrm{B}$ a u $\mathrm{mgarten}{ }^{10}$, welcher in aseptisch doppelt unterbundenen Gefägen keine Blutgerinnung beobachten konnte. Aus alledem geht hervor, daß Kretz die Thrombosenbildung im Venensystem in erster Linie oder doch im wesentlichen für einen Fibringerinnungsprozeß ansieht.

Im selben Jahre hat sich A s e h of $\mathfrak{f}^{16}$ gegen die $\mathrm{K} \mathrm{r}$ e $\mathrm{t} \mathrm{z}$ sehe Meinung über die Thrombenbildung bestimmt geäußert und sieh bemüht, mit seiner früheren genauen, grundlegenden Analyse des Aufbaues der Thromben, die Wichtigkeit der mechanischen Momente für die Entștehung der Thrombose darzulegen. Er betont, daß er niemals die Möglichkeit einer physikalischen Erklärung der Thrombosenbildung ans dem Auge verloren hat.

$\mathrm{Z}$ ur hell $\mathrm{e}^{17}$ hat danach in As ch of f s Institut zahlreiche Experimente gemacht und konnte bestätigen, daß die Bildung von Abscheidungsthromben in ganz der gleichen und gesetzmäßigen Weise geschieht, gleichviel, ob sterile oder infizierte Seidenfäden durch das Gefäß hindurchgelegt werden oder die Wand einfach mechanisch oder entzündlich in ihrer Struktur verändert wird, so daß für alle diese Fälle die durch das Experiment geschaffene Stromveränderung das Wesentliche ist.

Neuerdings hat $\mathrm{Kusama}{ }^{18}$ bei $\mathrm{Asch}$ of f eine Arbeit ïber die Thrombosenbildung, allerdings vom toxischen Standpunkte aus, geschrieben; nach ihm gibt es Plättchenthromben, für deren Entstehung eine primäre Endothelschädigung in keiner Weise in Betracht kommt.

Der Hauptstreitpunkt besteht im allgemeinen darin, daß einzelne Autoren das mechanische Moment als die letzte Ursache für die Thrombenbildung auffassen, während die andern Endothelschädigung für die wichtigste halten.

Auf Anregung von Herrn Geheimrat Ribbert habe ich die Bedeutung des infektiösen Momentes für die Thrombose experimentell zu klären versucht. Bevor ich auf die eigenen Experimente eingehe, möchte ich kurz auf die Literatur eingehen.

Es ist uns bekannt, daß eine Reihe von Autoren, nämlich von den deutschen Chirurgen Fränkel 19, Wiesel, Rehn, Lauenstein, Hochenegg, Schrötter, Mende ${ }^{20}$ und von den Gynäkologen Veit, Fromment, Bumm ${ }^{22}$, S inger ${ }^{22}$, Schata ${ }^{24}$, Remmer ${ }^{25}$, Thorel ${ }^{26}$, Meriell ${ }^{27}$, Duncan und IIImann ${ }^{28}$, Wertheim ${ }^{29}$, M o or e ${ }^{30}$, Ried el ${ }^{31}$, Sutton ${ }^{32}$, Len ander ${ }^{33}$ usw. und von den französischen Autoren Cornil ${ }^{34}$, Widal ${ }^{35}$, V a g u e $z^{36}$ usw. der Ansicht sind, dab die Infektion in der Ätiologie der Thrombenbildung die Hauptrolle spiele. Ferner stimmen einzelne Pathologen mit den oben erwähnten Autoren überein.

Die Bedeutung der Infektion für die Thrombose kann von zwei verschiedenen Gesichtspunkten aus beurteilt werden:

Lokale Thrombenbildung, auf Grund einer infektiösen Gefäßwandentzündung, und die Thrombenbildung entfernt vom Orte dex primären Infektion, auf grund allgemeiner Blatinfektion.

Im Jahre 1905 fand $\mathrm{Lu} \mathrm{b}$ a r s $\mathrm{ch}^{37}$ bei seinen Experimenten an Kaninchen, welche in der zentralen und peripherisehen Doppelunterbindung der Jugularis bestanden, daß das Blut nach 24 Stunden noch ganz flüssig geblieben war. Er spritzte sodann in Kochsalzlösung suspendierte 
Staphylokokken, Streptokokken, Diphtheriebazillen oder Bacterium coli in die Bauchhöhle oder V. cruralis oder auricularis ein. Bei direkter Einführung der frischen, von menschlichen Krankheitsfällen stammenden Kulturen in die Venen wurden mehr Thromben beobachtet als beim Einbringen in die Bauchhöhle, aber außer den Staphylokokkenversuchen verliefen die meisten Versuche negativ.

v. B a r d e I e b e ${ }^{38}$ untersuchte im Jahre 1907 die Wechselbeziehung zwischen Streptokokken und Gerinnung in der ruhenden oder stillstehenden Blutsäule, die zwischen zwei Unterbindungsligaturen einer Ohrvene des Kaninchens liegt und wochenlang, ja monatelang nicht gexinnt, worauf $\mathrm{B}$ a $\boldsymbol{u} \mathrm{m} \mathrm{g}$ a $\mathrm{rt} \boldsymbol{\theta} \boldsymbol{n}^{10}$ zuerst aufmerksam gemacht hatte. Bei Einbringung von Streptokokken in dieses Gefäßgebiet trat die Thrombenbildung, besser gesagt, die Gerinnung regelmäßig ein, ganz gleichgültig; ob die Kokken hoch virulent oder avirulent waren. Zur Klärung der Frage, auf welche Weise die Entstehung der Thromben bewirkt wird, hat er verschiedene Experimente angestellt und behauptet, daß die Leukozyten die Hauptquelle für das Fibrinferment sind. Er beobachtete bei der mikroskopischen Untersuchung der erhaltenen Thromben reichliche Leukozytenansammlung und Zerfall der Leukozyten und agglutinierte Erythrozyten und glaubte dadurch den sicheren Beweis erbracht zu haben, daß die Thromben in einer stehenden Blutsäule vor allen Dingen dem beim Kampfe zwischen Kokken und Leukozyten aus dem letzteren frei gewordenen Fibrinferment und in zweiter Linie der Agglutination der Erythrozyten, die ebenfalls durch Toxine der Bakterien verändert werden können, ihre Entstehung verdanken.

$\mathrm{J}$ a k o w s y ${ }^{39}$ erzielte nach Einbringung von Mikroorganismen in Reinkulturen in die Blutbahn eines Tieres (Ohrvene bzw. sublutanes Gewebe) unter gleichzeitig hervorgerufenen Zirkulationsstörungen bzw. leichten Traumatisierungen einer Vene an einer andern Körperstelle des Versuchstieres, in dieser letzteren (Krural- oder Ohrvene) in der großen Mehrzahl der Versuche Venenthrombose. Er verwendete in einer ersten Versuchsreihe Bacterium coli, in einer zweiten Diphtherie- und Typhusbazillen, sämtlich in Reinkulturen, sowie ihre Toxine. Um den Bakterien die Ansiedlung zu erleichtern, also gewissermaßen einen Locus minoris resistentiae zu schaffen, nahm er an Venen einer andern Körperstelle einen mechanischen Insult vor (Umschnürung bzw. Verlangsamúng des Blutstromes durch Umschnürung der Glieder mit einer Gummibinde). Durch diese Kombination ist ihm in der großen Mehrzahl seiner Versuche die Erzeugung von Thromben gelungen. Die Gerinnsel waren rot, zeigten geschichteten Ban; die eingeführten Mikroorganismen wurden nachgewiesen. Nach ihm ist die Entstehungsweise der Thromben so zu erklären, daß die Bakterien sich bei der Stromverlangsamung und bei der Läsion der Intima (Umschnürung, Kneifen) auf der GefäBwand leichter ansiedeln können und ihre Toxine produzieren, welch letztere die Gerinnung im Blute hervorbrachten.

L o e $b^{40}$ wies durch seine zahlreichen Experimente nach, daB gewisse Bakterien, vor allem Staphylococcus pyogenes in vitro, die Gerinnung von Tierblut beschleunigen können. Diese Resultate kritisierte $Z$ a r h ell e und sagte, dab die Mikroorganismen für die Frage der Beziehung zur Entstehung der Thrombose keine Bedeutung hätten. Denn Thrombenbildung im strömenden Blut hat mit Fibringerinnung, wie Pitres, Eberth und Sehimmelb us ch betont haben und wie die eigene Untersuchung $\mathrm{Z}$ urh elles zeigte, a priori gar nichts zu tun.

$\mathrm{ZurheIl} \mathrm{e}{ }^{17}$ betonte auf diese Weise, daß Allgemeininfektion direkt mit der Thrombenbildung nichts zu tun hat. Bei sehr schweren Infektionen können sekundäre Herzschwäche, Lähmung des Vasomotorenzentrums usw. zustande kommen, die eine Thrombenbildung begünstigen können. Er fügte dann hinzu, daß lokale Infektion, die auf die Venenwand übergreift, selbstverständlich zu lokalen Thrombosen führen und sich in einzelnen Fällen im Zusammenhang fortsetzen kann. Aber es liegt kein Zweifel dafür vor, daß entfernt vom Orte der Infektion die Mikroorganismen Thrombose hervorrufen können.

Welch ${ }^{41}{ }^{42}$ beobachtete bei frischen typhösen Gefäßveränderungen oft das Fehlen von 
Bakterien und ist deshalb der Ansicht, daß die Bakterien selbst nicht Thrombenbildung bei verschiedenen Infektionskrankkheiten - Typhus, Diphtherie, Variola usw. - hervorrufen.

J. F r o m m e ${ }^{43}$ teilte auf der Kölner Naturforscherversammlung mit, daB er an Kaninchen sterile und infizierte Fäden durch die Jugularvenen legte, welche im. Gefäß liegen blieben. Bei sterilen wurde niemals Thrombose des betreffenden Gefäßes gesehen, sondern der Faden heilte ein, indem er mit Endothel überzogen wurde. War dagegen der Faden infiziert, so wurde in allen Fällen eine mehr oder weniger ausgedehnte Thrombose der Vena jugularis beobachtet. Bei Tieren, die durch chronische Blutverluste in einem stark anämischen Zustande waren, waren die steril eingelegten Fäden mit stärkeren weiBlichen Gerinnseln bedeckt, die nach F r o m me aus niedergeschlagenen weißen Blutplättchen bestanden, doch wurde eine richtige Thrombose bei ihnen nicht gesehen. Anders auch hier wieder bei infizierten Fäden, durch die sich ganz ausgedehnte Thromben hervorrufen ließen. Aus diesen Versuchen schließt F r o m me, daB die Infektion der Fäden mit Hand- und Luftkeimen genügt, um eine Thrombose der Vene hervorzurufen, vorausgesetzt, daß der nicht saubere Faden in eine Vene zu liegen kommt. Er glaubte deshalb, daß hauptsächlich aus der weiteren Verbesserung der aseptischen Maßnahmen ein Fortschritt in der Vermeidung der Thrombose zu machen sei. Gegen Fromme diskutierte $\mathrm{Zu} \mathrm{rhelle}$, da er die von From me aus den Ergebnissen seiner Tierversuche gezogenen Schlüsse für falsch hielt. Er betonte, daß, wenn es Fro m m e bei seiner Versuchsanordnung nicht gelungen ist, Thrombose ohne Infektion rein mechanisch zu erzeugen, so ist es doch vielleicht möglich, bei anderer Versuchsanordnung experimentell solche hervorzurufen. Z u $I$ h e I l e sagte dann, daß F r o m mes Versuche seiner Ansicht nach nur beweisen, daß lokale Infektion lokale Thrombose erzeugt und daB eine stärkere Anämie nach chronischen Blutverlusten (wohl durch die dadurch hervorgerufene Stromverlangsamung, vielleicht auch durch die bei Anämie beobachtete starke Vermehrung der. Blutplättchen) ein sehr günstiges Moment zum Entstehen von Thrombose abgibt.

Es sollen hier ferner noch zahlreiche Arbeiten hinzugefügt werden, in welchen es sich um den Zusammenhang zwischen der Entzündung der Gefäßwand und der Entstehung der Thrombose handelt.

Croc qu versuchte 1894 eine Arteriitis experimentell zu erzeugen, über deren Wesen im Gegensatze zu der eingehend bearbeiteten Endokarditis - Roben bach, Orth, Wy s ok owits ch - noch wenig bekannt war; er wollte die Frage beantworten, ob ein Trauma allein fähig ist, eine akute Arteriitis hervorzurufen, und ob ein von Infektion gefolgtes Trauma imstande ist, unter allen Umständen eine akute Arteriitis herbeizuführen. Er verletzte die Innenfläche der Aorta von Kaninchen mittels eines dünnen Troikars, der durch die rechte Karotis eingeführt wurde. 1 bis 4 Wochen später fand er, daß das Trauma an sich keine Arteriitis bewirkt hatte. Bei weiteren Versuchen wurden Mikroorganismen - Bacterium typhi, Bacterium coli, Staphylococcus pyogenes aureus, Bact. diphtheriae - intravenös injiziert. Trotzdem fand er noch keine Arteriitis. Endlich ließ er der Infektion eine Verletzung der Endothelien vorangehen, es entstand dann meist eine Arteriitis, und zwar bei Injektion mit Typhusbazillen in einem Viertel der Fälle, die übrigen Bakterien und Kokken bewirken oft schon in wenigen Tagen entzündliche Veränderungen an den verletzten Stellen, die in ihrem mikroskopischen Aussehen bald endokarditischen Wucherungen - vielleicht Thrombose -, bald mehr kleinen erhabenen Infiltrationen glichen.

Diese infektiöse Arteriitis könne auf zweierlei Weise zustande kommen, einmal wird der Mikroorganismus auf ein vorher für den Empfang vorbereitetes Gefäß implantiert oder aber die Mikrobengifte wirken auf das vorher alterierte Endothel; daß der Autor keine Thromben in seinen Versuchen fand, erscheint durchaus merkwürdig.

1905 hat $\mathrm{Rib} b$ e $\mathrm{t}^{45}$ in seiner Abhandlung „Beiträge zùr normalen und pathologischen Anatomie und Physiologie der Niere" beweisende Versuche gemacht. Diese Versuche wurden in der Weise vorgenommen, dab er um ein abgeschlossenes Stück der Nierenarterie eine schwache 
Lugolösung fließen ließ, welche 1 bis 2 Minuten in Berührung mit der Gefäßwand blieb, dann wurde die Zirkulation wieder freigegeben. Es bildete sich eine Periarteriitis ans, deren wesentlichstes Merkmal eine Ansammlung von multinukleären Leukozyten war, ferner eine Mesarteriitis, mitunter bei besonders intensiver Jodwirkung trat Nekrose und Thrombose auf. Aber anch ohne diese stärkeren Veränderungen entwickelt sich nach und nach eine Wucherung der Intima mit deutlichen Mitosen. Durch diese zellige Verdickung der Intima trat eine erhebliche Verengerung des Lumens ein.

Fre u d w e il e ${ }^{46}$ machte dieselben Versuche; die Einwirkung der Jodlösung dauerte auch bis drei Minuten. Die Präparate kamen nach 2 bis 28 Tagen zur Untersuchung. Es ist aber hierbei auffallend, daß Thromben in keinem einzigen Falle aufgetreten waren.

Er kam zu folgendem Resultate:

1. Innenwand: die Endothelzellen vergrößern und vermehren sich, die Gefäßinnenhaut wird viel zellreicher.

2. Media: die fixen Zellen quellen auf und vermehren sich und sind im Anfang der Entzündungserscheinung vergrößert.

3. Adventitia: die Zellen vermehren und vergrößern sich, auch hier sind es besonders die Endothelien der Iymphspalten, weniger die Zellen des Gerüstes. Der ganze Prozeß, soweit er exsudativer Natur ist, beginnt auch hier in der Adventitia, wo er die größte Ausdehnung annimmt. Aus der entzündlichen Adventitia wandern zahlreiche Leukozyten in die Media ein.

Y at sus h i r ${ }^{47}$ hat unter R i b b e r t zum Studium der Emigration die Venenwand mit Aleuronat umgeben und nach 2, 4,6 bis 72 Stunden untersucht. Er hat bei diesen Versuchen. schon nach 2 Stunden deatliche Emigration beobachtet, ohne daß sich eine Thrombusspur zeigte.

Es ist bis heute weder pathologisch-anatomisch noch experimentell eine einwandfreie Antwort auf die Frage gegeben, welchen Einfluß die pathogenen Mikroorganismen bei den in der Nähe von Gefäßwänden sich abspielenden Entzündungsund Eiterungsprozessen ausüben. Wir wissen heute, daß die akute Phlebitis fast ausschließlich durch Bakterien bzw. ihre Stoffwechselprodukte hervorgerufen wird. In der Wand und in den Thromben wurden zahlreiche Arten pathogene Bakterien aufgefunden: ferner sollen nach neueren Forschungen auch die bisher auf andere Entstehungsursachen zurückgeführten marantischen und Stagnationsthromben durch Mikroorganismen hervorgerufen sein (Mannaberg und B äumler). Doch ist die Frage, was für ein ursächliches Moment die Mikroorganismen für die dadurch entstandenen Thromben ausüben sollen, noch nicht endgültig entschieden. Diesem Gedanken entsprechend führte T a l k e ${ }^{48}$ wertvolle Experimente aus.

Er ging in der Weise vor, daB er bei Katzen und Hunden die V. jugularis, Karotiden oder die Schenkelgefäße unter sorgfältiger Vermeidung einer Verletzung der Gefäßwand selbst oder abgehender Ästchen freilegte und Partikel von Staphylokokkenreinkultur in ihrer Nähe deponierte. Nach 9 bis 94 Stunden wurden die Gefäße untersucht. In 13 Versuchen wurden 44 Gefäße, und zwar 13 Arterien und 31 Venen so behandelt. Thrombose wurde dabei 33 mal erzeugt, 11 mal in Arterien, $22 \mathrm{mal}$ in Venen. Die Thromben wurden 16 mal vollständig obturierend, in den übrigen 15 Fällen waren sie kleiner, 3 mal nur fadenförmig der Wand anhaftendes Gerinnsel. Sie waren 7 mal rot, 5 mal gelblichweiB, 21 mal gemischt. Die GefäBwandschichten befanden sich im Zustande mehr oder weniger hochgradiger Entzündung, zuweilen war es in der Gefäßwand selbst zur Bildung kleiner Abszesse gekommen, einer starken Erweiterung der Lymphspalten. Bis in das 
Gefäßlumen vorgedrungen und in den Thromben nachweisbar waren die Kokken 15 mal, 18 Thromben waren frei von Kokken. In den älteren Thromben fanden sich die Kokken häufiger als in den frischen. Jedenfalls war also die Berührung mit den Bakterien nicht die direkte Ursache der Thrombenbildung, nur indirekt gaben die Kokken die Veranlassung dazu. T a l ke stellt sich den Hergang so vor, daß die Bakterien den Chemismus der Gewebe und die Zusammensetzung der Gewebsflüssigkeit in erheblicher Weise verändern. Lange bevor die Bakterien selbst bis zum Gefäßlumen vorgedrungen sind, ist die pathologische Gewebsflüssigkeit, vielleicht mit toxischen Stoffwechselprodukten der Bakterien dahin gelangt und hat im Blut zum Zerfall der roten Blutkörperchen Veranlassung gegeben. Es entsteht zunächst eine Auflagerung von Blutplättchen auf der Intima, und daran schließt sich die Weiterentwicklung der Thrombose in der gewöhnlichen Weise an. Die frischeste, vom Verfasser beobachtete Thrombenbildung hatte nach 9 Stunden stattgefunden.

\section{Eigene Untersuchungen.}

Der Zweck unserer Untersuchung ist, die folgenden Fragen zu beantworten:

1. Ob sich durch infektiöse Prozesse in der Nähe einer Gefäßwand oder direkt an der Gefäßwand, ohne andere ursächliche Momente - Stromveränderung, Verletzung der Gefäßwand, chemische Veränderung. der Blutbestandteile usw. eine Thrombose in dem Gefäß erzielen läßt.

2. Wie sich hierbei die pathogenen Mikroorganismen für die Thrombose verhalten, d. h. ob die Bakterien zur Thrombenbildung eine direkte Beziehung haben.

3. Welche Bedeutung kommt der Stromverlangsamung, welche der Gefäßwandschädigung zu?

\section{Die Technik und Versuehsanordnung.}

$\mathrm{Zu}$ den Versuchen sind Kaninchen und Hunde in Anwendung gekommen. Es wurden die Bauch- und Halsvenen und die Schenkelarterien ausgewähIt. Vor der Operation war das Schneiden und Rasieren der Haare erforderlich. Während der Versuche muß man sich streng in acht nehmen vor jeder Schädigung der Hauptstämme und Kollateralen, die zu einer Veränderung des Blutdruckes führen können, da wir, wie oben erwähnt, ja gerade die Entstehung des Thrombus ohne mechanische Alterationen studieren wollten. Nach schonender Freilegung des betreffenden Gefäßes wurde dann direkt an der Gefäßwand sofort eine Platinöse Material der frischen Bakterienkultur Streptokokken, Staphylokokken und Pneumokokken - deponiert. Darauf wurde in gewissen Zeiträumen $1 / 2,1,2,4,6,8,10,12,14,16,18,20,24,32,48,72,96$ Stunden ein ungefähr $1 / 2 \mathrm{~cm}$ langes GefüBstückchen durch Doppelunterbindung herausgeschnitten. Boi Benutzung der Halsgefäße wurde das Versuchstier getötet. Das Material wurde sofort durch Z e n k e r oder Formalin fixiert und teils in Zelloidin, teils in Paraffin eingebettet. Die Stücke wurden meist in Serien geschnitten. Zur Färbung wurde Hämatoxylin, Eosin, van Gi es on und Weigertsche Fibrindarstellungsmethode benutzt. Die Bakterien wurden immer durch G r a m - oder L ö f $f$ l e $r$ sche Methode nachgewiesen.

\section{Versuchsreihe}

(mit Reinkultur des Streptococcus pyogenes albus auf Agar).

Nr. 1. V.D. (Versuchsdauer) 1/2 Stunde (op. 15. April 1913). MittelgroBes Kaninchen, V. epigastric. dext., Streptoc. pyog. aus 1 Tag alter Kultur.

Makroskopisch nichts Besonderes. 
Mikroskopisch nichts Besonderes.

Nr. 2. V.D. 1 Stunde (op. 15. April 1913). Dasselbe Kaninchen, V. epigastrica sinist. Strept. pyog. aus 1 Tag alter Kultur.

Makroskopisch nichts Besonderes.

Mikroskopisch: Die Emigration ist schon ein wenig zu sehen. Die Gefäßwand ist schon ein wenig von ausgewanderten polymorphkernigen oder multinukleären Leukozyten durchsetzt. Die Gewebsstruktur ist ganz intakt. An der Intimafläche heften sich Leukozyten in einer einfachen Reihe an, und zwar deutlich an der Seite des Bakteriendepots. Im GefäBlumen sind Leukozyten noch überall zerstreut vorhanden. Die Kokken durchsetzen noch njcht die Gefäßwand.

Nr. 3. V.D. 2 Stunden (op. 15. April 1913). Kaninchen, V. epigastrica dext., Streptoc. pyog. aus $\mathbf{1}$ Tag alter Kultur.

Makroskopisch nichts Besonderes.

Mikroskopisch: Die Emigration ist schon deutlich aufgetreten. Die ganze Gefäßwand und ihre Umgebung ist von zahlreichen Leukozyten stark durchsetzt. Aber nirgends ist Gewebsschädigung zu erkennen. Adventitia und Media färben sich ganz normal. An der Intimafläche heiten sich Leukozyten, teils in einfachen, teils in mehreren Reihen an, so daß die ganze Intimafläche uneben aussieht. In der Umgebung sind die kleineren Venen und Lymphgefäße mäßig entzündet. Die Kokken sind hierbei durch die ganze Gefäßwand hindurch bis ins Lumen, aber in der unmittelbaren Nähe der Intima spärlich erschienen. Die Leukozyten sind im GefäBlumen noch reichlich zerstrent vorhanden.

Nr. 4. V.D. 4 Stunden (op. 15. April 1913). Dasselbe Kaninchen. V. epigastrica sinist. Streptoc. pyog. alb.

Maǩroskopisch: Die Gefäßwand sieht etwas verdickt ans und ist mit wässerig-gelblichrötlichem Exsudat bedeckt.

Mikroskopisch: Die Gefäßwand ist serös durehtränkt. An der Adventitia sind reichliche Leukozyten wallartig angesammelt. Die Adventitia färbt sich aber normal. Die Media und Intima ist auch mäßig infiltriert, aber keine nekrotische Stelle ist sichtbar. An der Intimafläche heften sich Leukozyten fast in der ganzen Zirkumferenz, und zwar teils in einfacher, teils in mehrfacher Reihe an. Leukozyten sind auch im Lumen zerstreut. Die Kokken sind reichlich in der Gefäßwand, aber im Gefäßlumen nur spärlich nachzuweisen. Eine fadenförmige, etwas körnige, thrombusartige Masse ist im Lumen vorhanden.

Nr. 5. V.D. 6 Stunden (op. 16. April 1913). Kaninchen. V. epigastrica dext. Streptoc. pyog. aus 2 Tage alter Kultur.

Makroskopisch: Die Gefäßwand ist mäßig geschwollen und gespannt.

Mikroskopisch: Die Gefäßwand ist von Leukozyten stark infiltriert. Herdförmige Infiltration an der Gefäßwand ist hierbei von Nr. 4 zu unterscheiden. An der Intimafläche haften auch teilweise Leukozyten in einfacher Reihe an. Nirgends ist Nekrose in der Gefäßwand zu erkennen. Die Kokken drangen durch die Gefäßwand ein, aber im Gefäßlumen wurden keine nachgewiesen. Kein Thrombus.

Nx. 6. V.D. 8 Stunden (op. 16. April 1913). Dasselbe Kaninchen. V. epigastrica sinist. Streptoc. pyog. aus 2 Tage alter Kultur.

Makroskopisch: Die Gefäßwand ist stark geschwollen, prall gespannt und mit rötlichgelblichen, reichlichen Eiterexsudaten durchtränkt.

Miknoskopisch: Hochgradige Emigration ist an der benutzten Vene und an sonstigen kleinen Venen und Lymphgefäßen zu sehen. Die Gefäßwand ist mäBig verdickt und serös durchtränkt. Leukozyten sind teils diffus, teils gruppenweise in der Gefäßwand verteilt. Die Adventitia färbt sich etwas schwach, aber Nekrose ist nicht deutlich. An der verdickten Intimafläche haften Leukozyten an der Seite des Experimentes fleckweise an. Dadurch erscheint die Intimafläche auffallend uneben. Die Kokken sind im GefäBlumen, in der Nähe der Intimafläche, der Seite des 
Experimentes ganz spärlich isoliert vorhanden. Ferner sind kleinere Venen und Lymphgefäße stark dilatiert und deren. Wand stark infiltriert. Kein Thrombus.

Nr. 7. V.D. 10 Stunden (op. 18. April 1913). Mittelgroßes Kaninchen. V. epigastrica dext., Streptoc. pyog. ans 3 Tage alter Kultur.

Makroskopisch nichts Besonderes.

Mikroskopisch: Hochgradige Gefäßwandentzündung ohne Nekrose. An der Intimafläche heften sich ganz wenig Leukozyten an. Im Gefäßlumen sind wenig Leukozyten zerstreut vorhanden. Die Kokken lassen sich im Lumen nur spärlich nachweisen. Thrombusartige Masse aus zertrümmerten Erythrozyten.

Nr. 8. V.D. 12 Stunden (op. 20. April 1913). Dasselbe Kaninchen. V. epigastrica sinist. Streptoc. pyog. aus 3 Tage alter Kultur.

Makroskopisch nichts Besonderes.

Mikroskopisch: An einer Stelle der Venenwand zeigt sịch herdförmige Leukozyteninfiltration, welche bis zur Intimafläche reicht. Dieser infiltrierten Stelle entsprechend sitzen an der Intimafläche mehrfache Reihen von Leukozyten an. Die Kokken sind aber an dieser Stelle nur spärlich nachzuweisen und nicht im Gefäßlumen. Kein Thrombus.

Nr. 9. V.D. 14 Stunden (op. 22. April 1913). Kaninchen. V. epigastrica dext. Streptoc. pyog. wie bei Nr. 8 .

Makroskopisch: Operationswunde ist ziemlich stark vereitert. Die Gefäßwand ist stark geschwollen, prall gespannt und mit graugelblichem dickem Eiterbelag überzogen.

Mikroskopisch: An der freien Oberfläche der Vene ist wallartige Leukozytenanhäufung zu sehen. Die Adventitia und Media sind staxk von Leukozyten inflitriert und teilweise nekrotisiert, schwach tingiert. Die Intima ist nicht deutlich gewuchert. An der Intimafläche; der Seite des Experimentes, heften sich Leukozyten teilweise in zwei- oder dreifachen Reihen an. An der Intima zeigt sich eine kleine nekratische Partie. Eine fadenförmige, etwas körnige, schmutzig. aussehende Masse befindet sich im Lumen (zertrümmerte Erythrozyten?). Leukozyten sind noch wenig und zerstreut im Gefäßlumen vorhanden. Die Kokken sind in der Adventitia und Media reichlich vorhanden, aber in der Intima und im Gefäßlumen nicht nachgewiesen. Kein Thrombus.

Nr. 10. V.D. 20 Stunden (op. 24. April 1913). Dasselbe Kaninchen. V. epigastrica sinist. Streptoc. pyog. alb. aus 2 Tage alter Kultur.

Die Gefäßwand ist stark verdickt und von Eiterbelag überdeckt. Die Gefäßwand ist überall stark entzündet. Die Adventitia ist von Lenkozyten intensiv infiltriert und teils nekrotisch zerfallen. Die Zellen färben sich etwas schwach. Die Intima ist teils deutlich gewuchert, teils nekrotisch schwach gefärbt. An der gewucherten Intimafläche heften sich Leukozyten in zweifacher Reihe an. Im GefäBlumen, und zwar in der Nähe der Seite des Experimentes, sieht man eine kleine, ovallängliche, blaßweißlich gefärbte körnige Masse, welche bei starker Vergrößerung Blutplättchen entspricht. In der Plättchenanhäufung finden sich wenig Leukozyten. Diese Masse steht mit der entzündeten Intimafläche fest im Zusammenhang. Kein Fibrin. Im Gefäßlumen und in der erwähnten Plättchenanhäufung sind Kokken nicht nachzuweisen.

Nr. 11. V.D. 1 Tag (op. 26. April 1913). Kaninchen. V. epigastrica dext. Streptoc. pyog. alb. aus 2 Tage alter Kultur.

Makroskopisch nicht abweichend von Nr. 10.

Mikroskopisch: Die Gefäßwand ist stark infiltriert, die Media ist teils deutlich infiltriert, teils nekrotisch, sehwach gefärbt. Der Intimazustand ist nicht dentlich zu sehen, da an der Intimafläche reichliche Leukozyten fast in ganzer Zirkumferenz sich anheften. Fast in der Mitte des GeŁäBlumens befindet sich eine kleine dreieckige, blaßweiBliche, körnige Blutplättchenanhäufung mit wenig Leukozyten. Die Kokken sind nirgends im Gefüßlumen nachgewiesen.

Dasselbe Kaninchen. V. epigastrica sinist. 
Makroskopisch nichts Besonderes.

Mikroskopisch: Die Gefäßwand ist stark entzündet und teils nekrotisch zerfallen. Die Intima ist auch mehr nekrotisch. An deren Fläche heften sich reichliche Lenkozyten in mehrfachen Reihen an (der Beginn der Thrombose). Typische Thrombose ist aber nicht entstanden. Die Kokken durchsetzen die Gefäßwand, finden sich aber nicht im Gefäßlumen.

Nr. 12. V.D. 32 Stunden (op. 26. April 1913). Kaninchen. V. epigastrica dext. Streptoc. pyog. aus 3 Tage alter Kultur.

Makroskopisch nichts Besonderes.

Mikroskopisch: Die Gefäßwand ist ziemlich stark entzündet, färbt sich zum Teil schwach. An der Intimafläche der Stelle des Experimentès finden sich Blutplättchen fadenförmig niedergeschlagen, an deren Rändern sieht man wenig Leukozyten. Leukozyten heften sich an Intimafläche in einfacher Reihe an. Erythrozyten sind nirgends zertrümmert. Im Lumen sind keine Kokken.

V. epigastrica sinist.; der Befund ist ganz derselbe. Die Kokken sind im Gefäßlumen nicht nachzuweisen, aber sie waren spärlich in der Intima vorhanden.

Nr. 13. V.D. 2 Tage (op. 28. April 1913). Mittelgroßes Kaninchen. V. epigastrica dext., Streptoc. pyog. aus 4 Tage alter Kultur.

Makrospkoisch: Die Gefäße sind mit reichlichem Eiterexsudat durchtränkt.

Mikroskopisch: Die Wand ist stark entzündet. Die Adventitia zeigt sich ganz nekrotisch. Die Intima ist auch stark entzündet, aber wenig nekrotiseh. An deren Fläche heften sich reichliche Leukozyten in mehrfacher Reihe. In der Mitte des GefäBlumens befindet sich eine kleine blaßweiße, rundliche Blutplättchenanhäufung mit spärlichen Leukozyten. Die Kokken sind im Gefäßlumen ganz spärlich nachzuweisen.

V. epigastrica sinist. zeigt keine Besonderheit.

Die Kokken sind aber hierbei nicht im Lumen vorhanden. Kein Thrombus.

Nr. 14. V.D. 3 Tage (op. 30. April 1913). Kaninchen. V. epigastrica sinist. Streptoc. aus 4 Tage alter Kultur.

Makroskopisch nichts Besonderes.

Mikroskopisch: Die GefäBwand ist besonders stark von Leukozyten infiltriert. Eine Stelle zeigt dureh die ganze Wand herdförmige Leukozyteninfiltration, einem Abszesse entsprechend. Die Intima zeigt deutliche Nekrose, ohne Thrombose aufzuweisen. Es ist hierbei aber merkwürdig, daß eine kleine Vene, welche um die ganze Wand herum stark entzündet ist, in der Mitte ihres Lumens eine kleine ovale Blutplättchenanhäufung zeigt, in węlcher sich reichliche Leukozyten befinden. Die Kokken sind nicht im Lumen. V. Epigastrica dext. zeigt nichts Besonderes.

Nr. 15. V.D. 4 Tage (op. 30. April 1913). Kaninchen. V. epigastrica dext. und sinist. Der Befund ist ganz derselbe wie Nr. 14. Die Intima weist aber keine Nekrose auf. Die Kokken sind aber im Lumen ganz spärlich nachzuweisen. Kein Thrombus.

Nr. 16. V.D. 5 Tage (op. 31. April 1913). Kaninchen. V. epigastrica dext. und sinist. Das Kaninchen war schwer krank (allgemeine Infektion). Nach der Abtötung wurde das Gefäßstück herausgeschnitten. Die Wand ist teils recht stark, und zwar im ganzen Umfang, entzündet und teils nekrotisch zerfallen. An der Intimafläche heften sich Leukozyten in mehrfachen Reihen in der ganzen Zirkumferenz an, dadurch ist das betreffende Gefäßlumen verengt (beginnender Thrombus?). Keine Kokken sind im Lumen. Typischer Thrombus ist nicht vorhanden.

Bei den 16 Versuchen der ersten Reihe mit insgesamt 32 Gefäßstückchen war die Thrombenbildung äußerst gering, wenn man die blaßweißlich gefärbte, körnige Masse im Gefäßlumen der Versuche 10, 11 und 13 überhaupt als Thrombus bezeichnen will. Dieses Resultat ist um so erstaunlicher, als doch Talke zahl- 
reiche positive Ergebnisse erzielte. Daß $\mathrm{T}$ al k e Hals- und Schenkelgefäße benutzte, während ich Bauchvenen vorzog, kann den Unterschied im Erfolge wohl nicht bedingen; dagegen ist von Wichtigkeit, daß $\mathrm{T}$ a $1 \mathrm{k}$ e Hunde und Katzen als Versuchstiere mit Staphylokokken behandelte, während ich Kaninchen und Streptokokken verwandte. Es ist ja bekannt, daß Kaninchen gegen Streptokokken nicht so empfindlich sind; das seheint aber in meinen Versuchen eine geringe Rolle gespielt zu haben, da die Gefäße sehr deutliche Entzündungserscheinungen, zum Teil mit Eiterung, zeigten. Es kam dagegen nicht zur Abszeßbildung in der Gefäßwand mit Perforation ins Lumen, wie bei $\mathrm{T}$ a $\mathrm{l} \mathrm{ke}$.

Die blaßweißlichen Anhäufungen im Gefäßlumen bei drei Versuchen halten wir für beginnende Thrombose; im normalen Querschnittbilde eines Gefäßes kommt ähnliches jedenfalls nicht vor. Man sieht allerdings bei Zertrümmerung von Erythrozyten ähnliche Bilder, sie lassen sich aber meist durch blaßrötlich gefärbte Reste oder Übergangsform zu roten Blutkörperehen von Plättchenmassen unterscheiden.

Agonale Abscheidungen kommen bei unserer Versuchsanordnung auch nicht in Betracht. Ich halte die Masse daher für intra vitam entstandene Blutplättchenthromben. Sie sind ganz blaßviolott, fein gekörnt und von Leukozyten wenig durchsetzt, während nach $\mathrm{R} 0$ st sich bei der agonalen Thrombose die Leukozyten nur auf der Oberfläche niederschlagen.

Es fragt sich nun, welche Bedingungen in unseren Versuchen zur Thrombenbildung geführt haben. Man muß in erster Linie an zwei Faktoren denken:

1. direkte Einwirkung der Bakterien auf das Blut selbst,

2. indirekte Einwirkung, d.h. Gefäßwandschädigung durch Bakterien oder Bakterientoxine.

ad 1. Eine direkte Einwirkung der Bakterien auf das Blut scheint mir in unseren Versuchen nicht in Betracht zu kommen, da gerade in den Versuchen, die zur Thrombenbildung führten, Bakterien weder im Thrombus noch im Gefäßlumen nachgewiesen werden konnten.

ad 2. An eine indirekte Einwirkung ist sehr wohl zu denken. Talke führte die Thrombenbildung auf eine Veränderung des Chemismus und der dadurch entstandenen Veränderung der Zusammensetzung der Gewebsflüssigkeit zurück. Dadurch soll zuerst Zerfall der roten Blutkörperchen eintreten und dann sollen sich auf der Intimafläche Blutplättchen ablagern; daran sehließt sich dann die Entwicklung des Thrombus in der gewöhnlichen Weise an.

Diese Erklärung scheint mir im ganzen zutreffend. Nur glaube ich, daß eine einfache Intimaveränderung, ein Verlust ihrer Glätte durch Nekrose oder Wucherung schon genügt.

Auf diese veränderte, uneben gewordene Intimafläche würden Blutbestandteile, erst Blutplättchen, in mechanischer Weise, wie in der Auffassung Ribb e r ts, niedergeschlagen und die weitere Grundlage für Abfallen der sonstigen 
Blutelemente bilden. Ich habe aber in der ersten Untersuchung nicht immer Intimanekrose gefunden, somit könnte man sagen, daß die Erklärungsweise nicht immer zutreffend sei. Aber es ist in Betracht zu ziehen, daß wir in einem solchen Falle die primäre Entstehungsstelle nicht getroffen haben, sondern irgendeine nekrotisierte Stelle bei der Untersuchung übersehen haben, also sekundär entwickelte Thrombusteile gerade in den Schnitt bekommen hätten. Um meine Versuche den positiven Experimenten T alkes möglichst ähnlich zu machen, habe ich eine zweite Versuchsreihe ausgeführt.

\section{Versuehsreihe.}

Es wurden als Versuchstiere Kaninchen benutzt, als Gefäße die Halsvenen. Als Infektionsmaterial ist Staphylokokkenreinkultur auf Agar in Anwendung gekommen. Nach dem Kurzschneiden der Haare in der vorderen Halsgegend wurde ein etwa 2,5 cm langer Längsschnitt ohne Narkose in der Mitte geführt. Beiderseits durchschimmernde Venen wurden entsprechend der Hauptschnittlänge unter strengster Vermeidung der Verletzung der Stämme und Seitenäste isoliert und eine Platinöse Material direkt an der Gefäßwand deponiert.

Nr. 1. V.D. 2 Stunden (op. 5. Mai 1913). Kaninchen. V. jug. dext. Staphyloc. pyog. (Reinkultur) auf Agar aus 1 Tage.

Mikroskopisch: Geringe Emigration, keine Gefäßwandnekrose, Leukozyten heften sich spärlich in einfacher Weise an der Intimafläche an. Keine Zertrümmerung der Blutkörperehen. Kein Thrombus. Im Gefäßlumen sind keine Kokken vorhanden.

V. jug. sinist. zeigt nichts Besonderes.

Nr. 2. V.D. 4 Stunden (op. 6. Mai 1913). Kaninchen. V. jug. dext. Staphyloc. pyog. alb. aus 2 Tage alter Kultur.

Makroskopisch nichts Besonderes.

Mikroskopisch: Deutliche Emigration. Die Gefäßwand ist an der Seite des Experimentes schon mäßig von Leukozyten infiltriert. Keine Wandschädigung. Färbung ist normal. Die Kokken sind in der Media ganz spärlich nachzuweisen, im Lumen aber nicht. Keine Zertrümmerung der Blutkörperchen. Kein Thrombus. V. jug. sinist. zeigt nichts Besonderes.

Nr. 3. V.D. 6 Stunden (op. 8. Mai 1913). Kaninchen. V. jug. dext. Staphyloc. pyog. aus 3 Tage alter Kultur.

Makroskopisch: Die Gefäßwand ist von reichlichem Exsudat durchtränkt.

Mikroskopisch: Die Adventitia ist von reichlicher Leukozytenansammlung durchsetzt. Die Media ist auch ziemlich deutlich infiltriert. An der Intimafläche heften sich Leukozyten, aber zirkumskript und meist in mehrfachen Reihen an. Keine nekrotische Stelle, K o k k e $n$ sind in der Media reichlich nachzuweisen. Kein Thrombus. V. jug. sinist. nichts Besonderes. Die Kokken sind nur wenig in der Media nachzuweisen.

Nr. 4. V.D. 8 Stunden (op. 9. Mai 1913). Kaninchen. V. jug. dext. Staphyloc. pyog. alb. aus 4 Tage alter Kultur.

Makroskopisch: Die Gefäßwand ist mäßig geschwollen und mit gelblichrötlichem Exsudạt durchtränkt.

Mikroskopisch: Die Gefäßwand ist serös durchtränkt und sieht verbreitert aus. Die Adventitia ist von Leukozyten stark bedeckt. Die Zellen sind hie und da nekrotisch zerfallen und schwach tingiert. Die Media ist stark entzündet. Die Intima ist wenig infiltriert. Leukozyten heften sich an der Intimafäche, teils in einfacher, teils mehrfacher Reihe an. Die Kokken sind 
in der Intima und im Gefäßlumen negativ. Kein Thrombus. V. jug. sinist. nichts Besonderes. Zertrümmerte rote Blutkörperchen sind in der Mitte des Lumens zu sehen.

Nr. 5. V.D. 10 Stunden (op. 12. Mai 1913). Kaninchen. V. jug. dext., Staphyloc. pyog. alb. aus 2 Tage alter Kultur.

Makroskopisch: Die Gefäßwand ist mäßig geschwollen und mit eitrigem Exsudat bekleidet.

Mikroskopisch: Keine Verschiedenheit von Nr. 4. Aber die Kokken sind im Gefäßlumen, doch in der Nähe der entzündeten Intima nur wenig nachgewiesen. Sie waren auch in der Gefäßwand nicht reichlich vorhanden. Kein typischer Thrombus. Eine kleine fadenförmige, thrombusartige Masse ist in der Nähe der Intima vorhanden.

V. jug. sinist. nichts Besonderes. Aber Intimawucherung ist ziemlich deutlich zu sehen. Wenig Fibrinmasse ist vorhanden.

Nr. 6. V.D. 12 Stunden (op. 13. Mai 1913). Kaninchen. V. jug. dext., Staphyloc. pyog. alb. aus 3 Tage alter Kultur.

Keine merkliche Verschiedenheit von Nr. 5. Im Gefäßlumen ist auch reichliche Fibrinausschwitzung zu sehen. Keine Kokken im Gefäßlumen. Kein Thrombus, eine fadenförmige, schmutzig aussehende Masse ist im Lumen vorhanden (zertrümmerte Erythrozyten).

Nr. 7. V.D. 14 Stunden (op. 13. Mai 1913). Kaninchen. V. jug. sinist., Staphyloc. pyog. alb. aus 3 Tage alter Kultur.

Makroskopisch: Die GefäBwand ist beträchtlich geschwollen und mit Eiterexsudat überzogen.

Mikroskopisch: Die Gefäßwand ist überall stark entzündet. Die Adventitia ist von Leukozyten außerordentlich stark infiltriert, teils nekrotisch, die Media ist schwach tingiert. Intima ist teils deutlich gewuchert, stark gefärbt, teils nekrotisch blaßi. An der Intimafläche heften sich. nur spärliche Leukozyten an. Im Gefäßlumen befindet sich eine große ovallängliche, blaßweißlich gefärbte, feinkörnig aussehende Blutplättchenanhäufung, welche teils mit der Intimafläche, teils mit Venenklappen lockeren Zusammenhang aufweist. Auf der Oberseite des Plättchenthrombus finden sich wenige Leukozyten. Kokken waren nur in der Media und Adventitia vorhanden. V. jug. dext. ist stark entzïndet. Kein Thrombus. Keine Kokken im Gefäßlumen.

Nr. 8. V.D. 16 Stunden (op. 16. Mai 1913). Kaninchen. V. jug. dext. Staphyloc. pyog. alb. ans 1 Tag alter Kultur.

Makroskopisch kein Unterschied von Nr. 7.

Mikroskopisch: Die Gefäßwand ist sehr stark entzündet. Die Media ist teils stark infiltriert, teils nekrotisch, schwach tingiert. Die Intima ist mäßig gewuchert, hier und da strukturlos, schwach gefärbt. An der nekrotischen Intimafläche festsitzend, befindet sich eine kleine ovale, mit reichlichen Leukozyten untermischte Blutplättchenanhäufung, ein Teil in Verbindung mit Venenklappen. Leukozyten heften sich an der Intimafläche ganz wenig an. Keine Kokken im Gefäßlumen. Kein Fibrin.

V. jug. sinist. zeigt deutliche Intimawucherung. Sonst nichts Besonderes. Geringe Zerstörung der roten Blutkörperchen.

Nr. 9. V.D. 20 Stunden (op. 17. Mai 1913). Kaninchen. V. jug. dext., Staphyloc. pyog. alb. aus 2 Tage alter Kultur.

Makroskopisch: Die Gefäßwand ist mäßig geschwollen, prall gespannt und mit xeichlichem eitrigem Exsudat übędeckt.

Mikroskopisch: Die Gefäßwand ist stark von Leukozyten infiltriert. Die Adventitia ist zum Teil nekrotisch, schwach gệärbt. Die Intima ist wenig gewuchert, und an ihrer Fläche heften sich Leukozyten in mehrfachen Reihen aber fleckweise an. Intimanekrose ist ziemlich deutlich nachzuweisen. Im Gefäßlumen, etwa in der Mitte, befindet sich ein kleiner, mit wenig Leukozyten versehener, unregelmäßig gestalteter Plättchenthrombus, welcher mit der Intimafläche nirgends zusammenhängt, die Blutkörperchen sind nicht zertrümmert. Kokken sind im Lumen nicht nachgewiesen. 
Nr. 10. V.D. 1 Tag (op. 19. Mai 1913). Kaninchen. V. jug. sinist. Staphyloc. pyog. aus 4 Tage alter Kultur.

Makroskopisch nichts Besonderes.

Mikroskopisch: Die Gefäßwand ist außerordentlich stark entzündet. Die Intima ist teils gewuchert, teils schwach gefärbt, nekrotisch. Im Gefäßlumen befindet sich in der Nähe der geschädigten Intima ein grober, mit wenig Leukozyten vermischter Blutplättchenthrombus, welcher sich mit der Intima nicht verbindet, aber an einer Venenklappe festsitzt. Geringe Zerstörung der roten Blutkörperchen. Die Kokken sind im Lumen und im Thrombus selbst auch nicht nach: zuweisen. In V. jug. dext. kein Thrombus.

Nr. 11. V.D. 1 Tag (op. 20. Mai 1913). V. jug. sinist. Staphyloc. pyog. alb. aus 5 Tage alter Kultur.

Makroskopisch niehts Besonderes.

Mikroskopiseh: Die Gefäßwand ist sehr stark entzündet. In der Intima ist nirgends Nekrose. An der entzündeten und mit Leukozyten besetzten Intimafläche sieht man eine große, feinkörnige, bogenförmige Masse, welche an ihrem Ende in einfacher Reihe Leukozyten besitzt (Blutplättchen?). Im Gefäßlumen sind zwei Stellen mit Leukozytenanhäufungen. Die Kokken sind in der Adventitia und Media nachzuweisen. V. jug. dext. zeigt ausgedehnte Intimanekrose, kein typischer Thrombus.

Nr. 12. V.D. 1 Tag (op. 20. Mai 1913). Kaninchen. V. jug. dext. Staphyloc. pyog. alb. aus 6 Tage alter Kultur.

Makroskopisch: Die Gefäßwand ist mit dickem Eiter belegt.

Mikroskopisch: Die Gefäßwand ist stark entzündet und teils verdickt. Die Intima teils gewuchert, teils nekrotisch. schwach tingiert. Kein typischer Thrombus. An der Wurzel einer Klappe befindet sich eine kleine ovale Plättchenanhäufung, mit wenigen Leukozyten. Die Kokken sind nicht im Lumen.

Nr. 13. V.D. 1 Tag (op. 22. Mai 1913). Kaninchen. V. jug. dext. und sinist. Staphyloc. pyog. alb. aus 2 Tage alter Kultur.

Makroskopisch: Die Gefäßwand ist mäßig geschwollen und mit reichlichem Eiter durchtränkt.

Mikroskopisch: Die Gefäßwand ist stark entzündet. Die Intima ist deutlich gewuchert, aber nicht nekrotisch. Kokken sind nur in der Adventitia und in der Media zu finden. Keine Blutbestandteile sind zerstört. Kein Thrombus. V. jug. sinist. An der entzündeten Intimafläche heften sich reichliche Leukozyten an, an einer Stelle pilzförmig.

Nr. 14. V.D. 11/2 Tage (op. 24. Mai 1913). Kaninchen. V. jug. dext. Staphyloc. pyog. alb. aus 4 Tage alter Kultur (das Tier wurde tot aufgefunden.)

Makroskopisch: Die Gefäßwand ist kollabiert und mit reichlichem Eiterexsudat überdeckt.

Mikroskopisch: Die Gefäßwand ist überall stark, teils diffus, teils herdförmig infiltriert. Die Intima ist meist deutlich gewuchert und teilweise nekrotisch. An der geschädigten Intimafläche heftet sich ein langes, dickes, bogenförmiges Blutgerinnsel an. In der Mitte des Lumens sieht man eine ovale, blaßweißlich gefärbte, homogene Masse mit schwach tingierten Leukozyten. (Blutplättchenanhäufungen?). Keine Kokken im Lumen. Keine Erythrozytenzerstörung.

Nr. 15. V.D. 2 Tage (op. 27. Mai 1913). Mittelgroßes Kaninchen. Jug. dext. Staphyloc pyog. alb. aus 2 Tage alter Kultur.

Makroskopisch nichts Besonderes.

Mikroskopisch: Die Gefäßwand ist stark entziündet. Die Media ist wenig nekrotisch, schwach gefärbt. Die Intima weist keine deutliche Nekrose auf. Leukozyten heften sich reichlich an dex entzündeten Intimafläche an. Fast in der Mitte des Lumens bemerkt man eine kleine ovale mit wenig Leukozyten versehene Blutplättchenanhäufung, welche sich mit der Intima nirgends in innigem Zusammenhang zeigt. Erythrozyten sind nicht zerstört. Die Kokken sind ganz wenig 
an der Intimafläche nachzuweisen. V. jug. sinist. weist eine unregelmäßig gestaltete thrombusähnliche Masse auf. Intima zeigt deutliche Nekrose.

Nr. 16. V.D. 2 Tage (op. 27. Mai 1913). Kaninchen. V. jug. dext. Staphyloc. pyog. alb. aus 5 Tage alter Kultur.

Makroskopisch nichts Besonderes.

Mikroskopisch: Die Gefäßwand ist auch stark, aber mehr herdförmig infiltriert, sonst nichts Besonderes. BlaBrötliche, körnige, fadenförmige Masse befindet sich fast in der Mitte des Lumens (Erythrozytenzertrümmerung). Keine Kokken im Lumen.

Nr. 17. V.D. 2 Tage (op. 3. Juni 1913). Kaninchen. V. jug. sinist. Staphyloc. pyog. alb. aus 2 Tage alter Kultur.

Makroskopisch: Die Gefäßwand ist stark geschwollen.

Mikroskopisch: Die Wand ist sehr stark entzündet. Die Intima ist nekrotisch und färbt sich schwach. Im Lumen ist keine Plättchenanhäufung, aber in einer kleineren Vene, die dicht bei der zum Versuche benutzten Vene liegt, und deren Wand stark entzündlich verändert ist, sieht man eine kleine, weißlich erscheinende Plättchenanhäufung, welche mit der Intimafläche einen lockeren Zusammenhang aufweist. Keine Kokken im Lumen. V. jug. dext. nichts Besonderes. In der Mitte des Lumens befindet sich eine kleine Leukozytenanhäufung.

Nr. 18. V.D. 3 Tage (op. 4. Juni 1913). Kaninchen. V. jug. dext. Staphyloc. pyog. alb. aus 3 Tage alter Kultur.

Wakroskopisch nichts Besonderes.

Mikroskopisch: Die GefäßBwand ist stark entzündet. Die Intima ist nicht nekrotisch. Kein Thrombus. Keine Kokken im Lumen. Jug. sinist. weist auch keine Thrombenbildung auf. In der Mitte des Lumens sieht man eine Fibrinmasse.

Nr. 19. V.D. 4 Tage (op. 7. Juni 1913). Kaninchen. V. jug. dext. Staphyloc. pyog. alb. aus 6 Tage alter Kultur.

Makroskopisch: Die Gefäßwand ist stark geschwollen, prall gespannt.

Mikroskopisch: Die Adventitia ist teils stark entzündlich infiltriert, teils nekrotisch schwach tingiert. Media ist auch stark infiltriert, aber nicht nekrotisch. Die Intima ist mäßig gewuchert, wenig nekrotisch. An der nekrotischen Intimafläche, und zwar in der ganzen Zirkumferenz, heften sich Leukozyten in einfachen Reihen an. Das Gefäßlumen scheint daher verengt. (Beginn des Leukozytenthrombus). Diese Lenkozyten sind zum Teil nekrotisch zerfallen. Im Gefäßlumen ist eine feine, reichliche Fibrinmasse. Die Kokken sind nirgends im Lumen nachzuweisen. V. jug. sinist. zeigt nichts Besonderes. Kein Thrombus.

Nr. 20. V.D. 5 Tage (op. 9. Juni 1913). Kaninchen. V. jug. sinist. Staphyloc. pyog. alb. aus 2 Tage alter Kultur.

Makroskopisch: Die Gefäßwand ist mit reichlichem Exsudat durchtränkt.

Mikroskopisçh: Gefäßwand ist auch stark entzündet, Leukozyten heften sich ganz wenig an. Die Intima ist mäßig gewuchert, aber nicht nekrotisch. An der infiltrierten Intimafläche sitat auch eine kleine halbkugelige, weißliche, kömige Masse (Plättchenthrombus) mit wenig Leukozyten. Keine Kokken im Iumen.

\section{Epikrise.}

Bei den 20 Versuchen der zweiten Reihe mit 40 Gefäßsstückchen, die den beiderseitigen Halsvenen zugehörten, wurden die Versuche im ganzen wie in der ersten Serie gemacht; nur wurde die Gefäßoberfläche von Zeit zu Zeit mit der Messerklinge einigemal gestrichen oder nach dem Deponieren der Bakterienkultur mit einer kleinen Sonde leicht gerieben, ohne erkennbare Wundverletzung herbei- 
zuführen, vom Gedanken ausgehend, daß die Bakterien dadurch etwas günstiger ins Lumen durchzukommen veranlaßt werden könnten und damit die Intima und das Blut besser von ihnen beeinflußt würde; ferner sei bemerkt, daß es hierbei immer mein Bestreben war, möglichst frische Reinkultur anzuwenden. Die über 6 Tage alte Kultur wurde hierbei niemals benutzt. Ganz merkwürdig ist es, daß hierbei verhältnismäßig viele Resultate erzielt wurden, von 40 Versuchen waren 8 Fälle (20\%) positiv. Diese 8 positiven Fälle zeigen eine Versuchsdauer von 14, 16, 20, 42 (2 Fälle), 96 und 120 Stunden. Der frischeste Thrombus ist erst 14 Stunden nach der Operation beobachtet worden. Was die Art der entstandenen Thromben anbetrifft, so sind 5 Blutplättchenthromben, 2 Leukozytenthromben und ein gemischter Thrombus entstanden. Vier von ihnen sind wandständig, während die andern drei (der eine ist ein gemischter Thrombus) mit der Intimafläche keinen oder nur geringen Zusammenhang aufweisen. Ferner wurde noch in 3 Fällen eine unregelmälig gestaltete weißliche, schmutzig aussehende, etwas körnige Masse ohne Leukozytenbeimischung meist in der Mitte des Gefäßlumens beobachtet (Erythrozytenzertrümmerung). Im allgemeinen sind die Thromben meist klein. Obliterierende Thromben wurden im Gegensatze zu T a $1 \mathrm{ke}$ in keinem einzigen Fall erzeugt. Nur der eine (gemischter Thrombus) hat höchstens etwa die Hälfte des betreffenden Lumenumfangs ausgefiillt. Ferner muß noch beigefügt werden, daß der Versuch Nr. 11 von 24 Stunden einen mächtigen, bogenförmigen, in der Nähe der Wand sitzenden Thrombus zeigte, der ïberhaupt nur aus Blutplättchen bestand und nur an seiner Oberfläche reichliche scharf erscheinende Leukozyten in einfacher Reihe erkennen ließ (agonale Entstehung?). Es fragt sich nun, warum in der zweiten Versuchsreihe im Verhältnis zur ersten so viele Erfolge erzielt wurden. Nach meiner Meinung hängt es in erster Linie damit zusammen, daß Staphylokokken bei Kaninchen viel virulenter wirken als Streptokokken, und daß die Halsvenen wegen des Vorhandenseins von Venenklappen für Thrombenbildung günstiger sind als die Bauchvenen. Erst entzündet sich die eigentliche Intima, dann geht die Entzündung weiter auf die Klappen zu. Ist eine Klappe entzündet, so wird das Niederschlagen der Blutelemente wahrscheinlich erleichtert sein. In den oben erwähnten 8 positiven Fällen sind die Intima, Adventitia und Media immer stark entzündet oder teilweise oder ausgedehnt nekrotisch. Die Thromben hatten sich meistens an der geschädigten Intimafläche gebildet, obwohl einige frei im Lumen gelagert waren. Es unterliegt also keinem Zweifel, daß die Thrombenbildung nicht durch direkte Einwirkung von Kokken, über welche ich nachher nochmals eingehend sprechen möchte, sondern erst durch ein indirektes Moment, nämlich durch eine nekrotische oder entzündliche Veränderung der Intima hervorgerufen werden muß, da in der zweiten Versuchsreihe, einige Fälle ausgenommen, keine Kokken im Gefäßlumen bzw. im Thrombus selbst nachgewiesen werden konnten. Die Kokken wurden nur in den 5 Fällen von 4, 6, 12, 24 und 72 Stunden ganz spärlich im Lumen aufgefunden. In der Intima waren sie 
8 mal, in der Media 12 mal nachgewiesen. Die Tatsache, daß die Kokken viel weniger in der zweiten Versuchsreihe im Lumen vorhanden waren, wird wohl auf die viel dickere, festere Wandbeschaffenheit der Halsvenen im Gegensatze zu derjenigen der Bauchvenen zurückzuführen sein.

\section{Versuchsreihe.}

Es wurden in diesen Versuchen Hunde benutzt; als Operationsstelle die Halsvenen. Als Infektionsmaterial ist auch Staphylokokkenreinkultur auf Agar in Anwendung gekommen. Die Operation wurde aber immer unter ganz leichter Äthernarkose ausgeführt. Die entsprechende Stelle wurde in Zeiträumen von 1 bis 5 Tagen herausgeschnitten und untersucht.

Nr. 1. V.D. 1 Tag (op. 12. Juni 1913). V. jug. dext., Staphyloc. pyog. alb. aus 2 Tage alter Kultur. schwollen.

Makroskopisch: Die Gefäßwand ist von reichlichem Exsudat durchtränkt und mäßig ge-

Mikroskopisch: Die Wand ist stark entzündlich infiltriert. Die Media färbt sich sehwach. Die Intima ist teils nekrotisch schwach tingiert, teils stark infiltriert und gefärbt. An der geschädigten Intimafäche heften sich reichliche Leukozyten in zwei- oder dreifasher Reihe an, und zwar auffallend viel an der Seite des Experimentes. Wenig Erythrozyten sind zertrümmert. Die Kokken sind in der Media und Adventitia spärlich nachgewiesen. Kein typischer Thrombus. V. jug. sinist. Die Wand ist ebenfalls stark entzündet. Im Lumen, und zwar in der Nähe der Seite des Experimentes, befindet sich eine kleine, schmale, lange, leicht körnige, blaßweißlich erscheinende Masse, in welcher sich keine Lenkozyten finden (Blutplättchenanhänfung?). Die Masse weist mit der Intima keinen innigen Zusammenhang auf.

Nr. 2. V.D. 1 Tag (op. 13. Juni 1913). V. jug. dext., Staphyloc. alb. aus 3 Tage alter Kultur.

Makroskopisch nichts Besonderes.

Mikroskopisch: Die Gefäßwand ist auch stark entzündet. Die Intima ist teils stark infiltriert, teils nekrotisch, schwach gefärbt. An der geschädigten Intimafläche heftet sich auch eine blaßweißliche, etwas körnige Masse ohne Leukozyten an. Keine Erythrozytenzerstörung. Die Kokken sind nirgends im Lumen nachzuweisen.

V. jug. sinist. weist nichts Besonderes auf. In einem kleineren GefäßBlumen befindet sich aber eine kleine ovale, mit Leukozyten versehene Blutplättchenanhäufung, welche mit der entzündeten Wand in lockerem Zusammenhang steht. Wenig Fibrinausschwitzung.

Nr. 3. V.D. 2 Tage (op. 15. Juni 1913). V. jug. dext, Staphyloc. pyog. alb. aus 5 Tage alter Kultur.

Makroskopisch nichts Besonderes.

Mikroskopisch nicht viel zu sehen.

V. jug. sinist. Die Wand ist stark entzündet, teils nekrotisch und schwach gefärbt. In der Nähe der entzündeten Intima befindet sich eine kleine, ovalrundliche, mit wenig Leukozyten versehene Plättchenanhäufung, welche keine Beziehung zur Intimafläche zeigt. Die Kokken sind in der Intima ganz spärlich zerstreut vorhanden.

Nr. 4. V.D. 2 Tage (op. 16. Juni 1913). V. jug. dext., Staphyloc pyog. alb. ans 6 Tage aiter Kultur.

Makroskopiseh nichts Besonderes. Kein typischer Thrombus. Keine Kokken im Lumen. Mächtiges langes Gerinnsel ist an der Intimafläche vorhanden.

Nr. 5. V.D. 3 Tage (op. 19. Juni 1913). V. jug. dext. Staphyloc. pyog. alb. aus 1 Tag alter Kultur.

Makroskopisch nichts Besonderes. 
Mikroskopisch: Die Wand ist außerordentlich stark infiltriert. Die Intima ist wenig nekrotisch. Kein Thrombus. Erythrozyten sind wenig zertrümmert. Keine Kokken im Lumen.

In V. jug. sinist. auch kein Thrombus.

Nr. 6. V.D. 4 Tage (op. 20. Juni 1913). V. jug. dext, Staphyloc. pyog. alb. aus 2 Tage alter Kultur.

Nichts Besonderes.

V. jug. sinist.

Makroskopisch: Die Gefäßwand ist mäßig geschwollen und mit reichlichem Eiterexsudat durchtränkt.

Mikroskopisch: Die Wunde ist überall stark infiltriert. Die Media ist nekrotisch. Die Intima ist teils mit Leukozyten infiltriert, teils nekrotisch. An einer Stelle der infiltrierten Intimafläche heften sich reichliche Leukozyten in mehrfacher Reihe an, welche schon wenig nekrotisch zerfallen sind (Beginn der Thrombenbildung?). Die Kokken sind nirgends im Lumen vorhanden. Kein typischer Thrombus.

Nr. 7. V.D. 5 Tage (op. 22. Juni 1913). V. jug. dext., Staphyloc. pyog. alb. aus 4 Tage alter Kultur.

Makroskopisch: Die Gefäßwand ist stark geschädigt. Media ist hie und da nekrotisch. Die Intima ist auch teils nekrotisch, teils stark infiltriert und wenig gewuchert. An der entzündeten Intimafläche heften sich Leukozyten in einfacher Reihe an. In der Nähe der entzündeten Intima befinden sich kleine ovale, mit wenig Leukozyten versehene Blutplättchenanhäufungen, die eine davon sitzt fest an der entzündeten Intima, die andere liegt frei im Lumen. Die Kokken sind im Gefäßlumen nicht aufzufinden. Frythrozyten sind nicht zertrümmert.

$$
\text { E p ikrise. }
$$

Es wurde in der dritten Versuchsreihe an 5 Hunden experimentiert, 10 Gefäßstïcke wurden untersucht. Es entstanden auch hier keine großen, deutlichen Thromben. Nur in 5 Fällen fand ich kleine ovale oder unregelmäßig gestaltete blaßweißliche Plättchenthrombenbälkchen, von welchen drei sich an der geschädigten Intima befanden, während die beiden andern frei von der Intima lagen. Ferner hefteten sich noch im Versuch Nr. 6 reichliche Leukozyten an der stark geschädigten Intima an, so daß das ganze Gefäßlumen rauh, zackig oder pilzförmig unèben aussah. Die Leukozyten sind teils nekrotisch zerfallen. Es sind keine roten Blutkörperchen, Blutplättchen oder Fibrin darin. Ich halte dieses Bild für einen Beginn von Thrombenbildung. Die andern vier genannten Thrombusmassen sollen auch hierbei als beginnende Thrombenbildung aufgefaßt werden. Auffällig ist, daß keine größeren Thromben zu sehen waren.

Womit soll man diese Tatsachen erklären? Die Frage könnte man vielleicht dadurch erklären, daß die Halsvenen der Hunde etwas dicker sind als diejenigen der Kaninchen und daher das Eindringen der Kokken einigermaßen erschwert wird, und die daraus resultierende Intimaschädigung nicht immer so intensiv war. Erythrozytenzertrümmerung wurde in 3 Fällen beobachtet, darunter einer mit Thrombenbildung. Es war mir aber niemals schwergefallen, diese Erythrozyten von den Plättchen zu unterscheiden. Die Kokken wurden im Gefäßlumen nur zweimal, in der Media auch zweimal, aber nur spärlich nachgewiesen. Die Kokken 
hatten offenbar auf die Thrombenbildung in diesem Versuche auch keinen direkten Einfluß ausgeübt.

\section{Versuchsieihe an Arterien.}

Der vierte Versuch wurde mit Staphylokokkenreinkultur auf Agar an der Karotis des Kaninchens und des Hundes gemacht. Es sei bemerkt, daB die Versuchsdauer hierbei bloß von 1 bis 5 Tagen sich erstreckte.

Nr. 1. V.D. 1 Tag (op. 24. Juni 1913). Kaninchen. A. carot. dext., Staphyloc, alb. aus 1 T'ag alter Kultur.

Makroskopisch: Die Wand ist etwas gesehwollen.

Mikroskopisch: Die Adventitia ist stark infiltriert. Die Media ist teils infiltriert, teils nekrotisch, schwach gefärbt. Die Intima ist wenig gewuchert. Nưr an der Intimafläche der Seite des Experimentes heften sich Leukozyten in mehrfacher Reihe an. Kein Thrombus. Die Kokken sind nur in der Adventitia reichlich und in der Media nur spärlich nachgewiesen, wenig Fibrinmasse. A. carot. sinist. nichts Besonderes.

Nr. 2. V.D. 1 Tag (op. 25. Juni 1913). Kaninchen. A. carot. dext., Staphyloc. pyog. alb. aus 2 Tage altre Kultur.

Makroskopisch nichts Besonderes.

Mikroskopisch: Dỉe Wand ist stark entzündet, an einer Stelle der Media herdförmige Leukozyteninfiltration; dadurch sieht die Media etwas verbreitert aus. An der etwas entzündeten Intimafläche finden sich reichlich Blutplättchen, diese Stelle ragt hügelig etwas nach dem Lumen vor. Kokken sind im Lumen nicht nachzuweisen. Erythrozyten sind wenig zertrümmert.

A. earotis sinist. zeigte keine Thrombenbildung.

Nr. 3, V.D. 2 Tage (op. 27. Juni 1913). Kaninchen. A. carot. dext, Staphyloc. pyog. alb. aus 4 Tage alter Kultur.

Nichts Besonderes.

A. carot. sinist., die Gefäßwand ist stark geschädigt. Die Media ist auffallend nekrotisch, ganz blaß tingiert. Die Intima ist auch sehr stark nekrotisch. An der nekrotischen Intimafläche, und zwar an der Seite des Experimentes, heften sich zahlreiche Leukozyten in mehrfacher Reihe an. Diese Leukozytenmasse nimmt ungefähr die Hälfte des ganzen Intimaumfangs ein. Diese Lenkozyten sind aber teils nekrotisch zerfallen, teils pyknotisch und stark gefärbt. Die Kokken sind wenig in der Adventitia und in der Media vorhanden. Der Leukozytenmasse sind mehr oder weniger Blutplättchen beigemischt.

Nr. 4. V.D. 3 Tage (op. 28. Juni 1913), Kaninchen. A. carot. dext., sinist. Staphyloc. pyog. alb. aus 5 Tage alter Kultur.

Makroskopisch: Die Gefäßwand ist hierbei schwach entzündet.

Mikroskopisch: Keine nekrotisehe Partie. Kein Thrombus. Die Kokken sind nur in der Adventitia nachgewiesen. Die Media und die Intima sind anffallend nekrotisch. An der nekrotischen Intimafläche sieht man in breitem Umfange eine reichliche Leukozytenanhäufung (Leukozytenthrombus). Fibrin ist nicht darin nachweisbar. Keine Kokken im Lumen. A. carot. sinist. zeigt auch einen derartigen Befund, aber hier ist noch außer dem wandständigen Thrombus ein kleiner Leukozytenthrombus zu sehen, welcher sich gerade in seiner Nähe gebildet hat. Keine Kokken im Lamen. Erythrozyten nicht zertrümmert.

Nr. 5. V.D. 3 Tage (op. 30. Juni 1913). Kaninchen. A. carot. dext. Staphyloc. pyog. alb. aus $1 \mathrm{Tag}$ alter Kritur.

Makroskopisch: Die Wand ist stark von Eiter äberdeckt.

Mikroskopisch: Die Wand ist auRerordentlich stark infiltriert. Die Intima und die Media zeigen ausgedehnte Nekrose. An der Intimafläche heften sich reichliche Leukozyten an. Kein Fibrin; Erythrozytenzertrümmerung ist nicht za sehen. 
Nr. 6. V.D. 4 Tage (op. 1. Juli 1913). Kaninchen. A. carotis sinist. Staphyloc. pyog. alb. aus 3 Tage alter Kultur. .

Makroskopisch nichts Besonderes.

Mikroskopisch: Die Gefäßwand ist in ihrem ganzen Umfange stark geschädjgt. Die Media ist teils nekrotisch, ganz sehwach tingiert, teils wenig infiltriert. Die Intima, vor allem auf der Seite des Experimentes, ist auch stark nekrotiseh und gar nicht gefürbt. An der nekrotischen Intima festsitzend, sieht man an zwei Stellen deutliche Blutplättchenthromben mit wenig Leukozyten, der eine ist halbkugelig, der andere zickzackähnlich. Der Thrombus geht allmählich in die nekrotische Intima über. Kein Fibrin im Thrombus. Erythrozyten nicht zertrümmert. A. carot. dext. Hier befindet sich keine so deutliche Thrombenbildung, aber an der nekrotischen Intimafläche heften sich Blutplättchen flächenweise in ziemlich großem Umfang an (Beginn der Plättchenthromben). Kokken sind in beiden Fällen nicht im Lumen nachzuweisen. Keine Erythrozytenzertrümmerung.

Nr. 7. V.D. 5 Tage (op. 3. Juli 1913). Kaninchen. A. carot. dext., Staphyloc. pyog. alb. aus 6 Tage alter Kultur.

Mikroskopisch: Die Wand ist außerordentlich stark entzündet und zeigt teilweise Abszeßbildung. Die Adventitia und Media sind schon fast überall nekrotisch, schwach tingiert, Intima zeigt auch ausgedehnte Nekrose. Elastische Fasern der Wand sind nicht mehr deutlich. An der Intimafläche sitzend befindet sich fast in ihrem ganzen Umfang reichliche Leukozytenanhäufung, welche pilzartig, kugelig oder zackig nach dem Lumen vorspringt. An der der Seite des Experimentes gegenüber liegenden Intimafläche sitzt noch ein ziemlich großer, längliehovaler Leukozytenthrombus mit wenig Plättchen, durch welchen die Hälfte des Lumens ganz obliteriert aussieht. Der Thrombus besteht hauptsächlich aus Leukozyten und wenig Blutplättchen. Er zeigt ein etwas faseriges Aussehen, aber Fibrin ist nicht nachweisbar. A. carot. sinist. zeigt auch ausgedehnte Nekrose. Fast am ganzen Umfange der nekrotischen Intima sitzen auch deutliche Thromben vorwiegend aus Leukozyten, welche pilzartig aus dem Lumen vorspringen oder mehr fläehenhaft sich ausbreiten, die Leukozyten sind aber mehr zerfallen, kein Fibrin dabei. Die Kokken sind in den beiden Fällen nirgends im Lumen nachzuweisen. In der Intima sind sie spärlich vorhanden.

Nr. 8. V.D. 5 Tage (op. 5. Juli 1913). Kaninchen. A. carot. dext., Staphyloc. pyog. alb. aus 8 Tage alter Kultur.

Makroskopisch michts Besonderes.

Mikroskopisch: Auffallende Wandnekrose. Die Intima zeigt keine intakte Stelle, färbt sich gar nicht. An dieser nekrotischen Intimafläche befinden sich drei Plättchenthrombenbalken, die eine ist halbkugelig und die andern beiden mehr breitbasig, zackig nach dem Lumen dentlich vorspringend. Der Thrombus sieht mehr weiBwolkig aus. Leukozyten sind ganz wenig darin. Kein Fibrin. Die Kokken sind nicht im Lumen nachzuweisen.

Nr. 9. V.D. 4 Tage (op. 29. Juli 1913). Junger Hund. A. femoralis, Staphyloc. pyog. alb. aus 3 Tage alter Kultur.

Makroskopisch: Die Gefäßwand ist mit reichlichem Exsudat durchtränkt.

Mikroskopisch: Die Gefäßwand ist stark entzündet. Die Adventitia ist von reichlichen Eiterkörperchen durchsetzt. Die Media ist teils infiltriert, teils schwach nekrotisch, bla.B tingiert, teils gar nicht gefärbt. Die Intima ist wenig zirkumskript gewuchert. Es ist aber in der Intima keine nekrotische Stelle erkennbar. Aus einer stark entzündlich infiltrierten Intimafläche, an der Seite des Experimentes beginnend, bildet sich ein mächtiger, gemischter Thrombus, der etwa über die Hälfte des betreffenden ganzen Arterienlumens einnimmt, aber nicht ganz obliteriert ist. Der Thrombus besteht aus Leukozyten, Blutplättchen und wenig Erythrozyten. Fibrin ist gar nicht darin nachzuweisen. Der Thrombus setzt sich an der entzündeten und nekrotischen Intimafläche fest. Kokken sind nirgends im Lumen vorhanden. 
E p ikrise.

Es wurde dieselbe Bakterienreinkultur, wie in den vorigen Versuchen angewendet, nur statt der Venen wurden Arterien benutzt. Für die Experimente wurden 8 Kaninchen und 1 Hund verwendet, von denen 1.8 Arterienstiicke untersucht wurden, darunter eins von der A. femoralis, während die übrigen 17 Karotiden waren. Die 18 Üntersuchungen ergaben 8 positive Fälle (57\%). Der frischeste Thrombus ist der von eintägiger Versuchsdauer (Blutplättchenthrombus).

Was die Art der Thromben anbetrifft, so sind 3 Leukozytenthromben und 5 Blutplättchenthromben entstanden. Unter diesen beobachtete ich eine kleine blaßweißliche Masse, die als ein Anfang von Plättchenthrombenbildung aufgefaßt werden soll. Interessant ist es, daß man fast immer an der Intima sitzende Thromben beobachtet hat. Die Kokken waren in keinem einzigen Falle im Arterienlumen oder in den Thromben selbst nachzuweisen; nur in 2 Fällen waren sie an den Intimaflächen ganz spärlich vorhanden. In der Media wurden sie 4 mal nachgewiesen. In der Adventitia waren sie ohne Ausnahme vorhanden.

Von diesem Befunde ausgehend, ist es klar, daß die Thromben nicht von der direkten Einwirkung der Bakterien resultieren konnten, sondern wir müssen diese Tatsache darauf zurïckführen, daß die sekundär eintretende Wandschädigung erst zur Thrombenbildung geführt hat. Merkwürdig ist, daß man trotz der weniger zahlreichen Versuche und der viel dichteren Wandstruktur der Arterien verhältnismäßig mehr Resultate erzielt hat. Ich glaube, diese Verschiedenheit damit erklären zu können, daß die Arterien sich viel tiefer als die Venen zwischen den umgebenden Geweben finden und infolgedessen die Eitermassen schwerer nach außen ausgeschieden werden können und dadurch die dazwischen liegenden Arterien von den Bakterien oder Toxinen viel stärker angegriffen werden können.

\section{Versuchseihe.}

$\mathrm{Zu}$ diesen Versuchen werden frische Pneumokokkenreinkulturen in Bouillonnährboden gebracht. Als Operationsstelle sind auch die Halsvenen angewendet worden.

Nr. 1. V.D. 1 Tag (op. 10. März 1913). ' Kaninchen. V. jug. dext. Pneumok. aus 2 Tage alter Kultur.

Makroskopisch: Die Gefäßwand ist mit rötlichgelblichem Eiterexsudat bedeckt.

Mikroskopisch: Emigration ist schon deutlich. In der Adventitia sammeln sich reichlich Leukozyten an. Die Media ist auch von Leukozyten infiltriert, sie färbt sich normal. Intima fast intakt. An der Intimafläche heften sich aber Leukozyten in einfacher Reihe an. Nirgends ist ein Thrombus zu sehen. Kein. Blutkörperchen ist zertrümmert. Die Kokken sind allein in der Adventitia lokalisiert. An einer Stelle der Intima sitzt ein großes langes Gerinnsel. V. jug. sinist. nichts Besonderes.

Nr. 2. V.D. 2 Tage (op. 12. Juli 1913). Kaninchen. V. jug. dext. Pneumokokken aus 4 Tage alter Kultur.

Makroskopisch und mikroskopisch nichts Besonderes.

V. jug. sinist. Die Gefäßwand ist ziemlich stark entzündet, färbt sich aber normal. Nirgends zeigt sich Nekrose. An der Intimafläche, welche in kleinem Umfang nekrotische Veränderung aufweist, schlagen sich wenig Blutplättchen in fadenförmiger Weise und mit wenig Leukozyten 
vermischt nieder, beginnende Thrombose. Blutkörperchen sind nirgends zertrümmert. Keine Kokken im Lumen.

Nr. 3. V.D. 4 Tage (op. 13. Juli 1913). Junger Hund. V. jug. dext., Pneumokokken aus 5 Tage alter Kultur.

Makroskopisch: Die Gefäßwand ist mit dickem, rötlichgelbem Exsudat überdeckt und mäßig geschwollen.

Mikroskopisch: Die Gefäßwand ist mäßjg infiltriert. Die Media färbt sich normal. Die Intima ist auch etwas infiltriert, doch ist keine nekrotische Stelle zu erkennen. An der entzündeten Intimafläche befindet sich eine kleine fadenförmige, weißlich körnige Masse (Blutplättchen), welche wenig Lenkozyten auf ihrer Fläche zeigt. Die Kokken sind nirgends zu sehen. Blutkörperehen sind nicht zertrümmert. V. jug. sinist. zeigt nichts Besonderes.

Nr. 4. V.D. 5 Tage (op. 15. Juli 1913). Kleiner Hund. V. jug. dext. Pneumokokken aus 7 Tage alter Kultur.

Mikroskopisch: In der Nähe der entzündeten Intima befindet sich eine kleine ovale Ieukozytenanhäufung. Sonst nichts Besonderes. V. jug. sinist. An der wenig nekrotischen Intimafiäche heften sich reichliche Leukozy ten an. Die Kokken sind im Lumen. Kein typischerThrombus.

\section{E p ikrise.}

In der 5. Versuchsreihe wurden insgesamt 8 Gefäßstücke bei 1 - bis 5 tägiger Versuchsdauer untersucht. Die Versuche sind hierbei wenig erfolgreich, abgesehen davon, daß die Versuche (Nr. 2 und 3 ) eine kleine fadenförmige Plättchenanhäufung an der entzündeten Intimafläche aufwiesen, welche ich auch als Thrombus ansehen will. Die Gefäßwandschädigung durch die Pneumokokken ist etwas geringer als in den Versuchen mit andern Eitererregern (Streptokokken und Staphylokokken). In den genannten Versuchsdauern ( 1 bis 5 Tagen) bemerkte ich in der Gefäßwand keine stärkeren nekrotischen Prozesse, wie es in den andern Versuchsreihen der Fall war. Die Emigration ist auch immer verhältnismäßig schwächer als jene. Die deponierten Pneumokokken waren in den genannten Zeitdauern fast immer an den eingebrachten Stellen lokalisiert, ohne die Media zu passieren oder durch die Intima durchzukommen.

\section{Zus a m menfassende Besprechung.}

Zur Übersicht habe ich eine Tabelle angefertigt. Aus dieser Tabelle geht außer der Zahl, der Versuchsdaner, dem Infektionsmaterial usw. - folgendes hervor:

Unter den 108 untersuchten Fällen sind nur 28 mal (26\%) Thromben gefunden worden. Es sei aber bemerkt, daß unter diesen Fällen nur diejenigen mitgerechnet worden sind, welche sicher für typische Thromben gehalten werden können, jene plättchenähnlichen, fadenförmigen fraglichen Anhäufungen sind dabei nicht mitgerechnet, da sie vielleicht Zerfallsmassen der Erythrozyten sein können.

Was die Art der entstandenen Thromben anbetrifft, so sind es 20 Blutplättchenthromben, 5 Leukozytenthromben und 3 gemischte Thromben. Rote Thromben, wie $\mathrm{T}$ a $1 \mathrm{k}$ e sie fand, sind in unseren Fällen nie beobachtet worden. Der frischeste Thrombus ist 20 Stunden alt (1. Versuchsreihe). Die Thromben sind in der Mehrzahl der Fälle klein, abgesehen von 2 Fällen, einer von der Vene, der andere von 


\begin{tabular}{|c|c|c|c|c|c|c|}
\hline $\begin{array}{c}\text { Ver- } \\
\text { suchs- } \\
\text { serie }\end{array}$ & $\begin{array}{c}\text { Ver- } \\
\text { suchs- } \\
\text { zahl }\end{array}$ & $\begin{array}{l}\text { Ver- } \\
\text { suchs- } \\
\text { daner }\end{array}$ & $\begin{array}{l}\text { Versuchs- } \\
\text { material }\end{array}$ & $\begin{array}{l}\text { Versuchs- } \\
\text { stelle }\end{array}$ & Resultat & Bemerkungen \\
\hline 1 & 32 & $\begin{array}{c}1 / 2 \mathrm{bis} \\
120 \mathrm{Std} .\end{array}$ & $\begin{array}{c}\text { Streptococc. } \\
\text { pyog。 }\end{array}$ & $\begin{array}{l}\text { Bauchvenen } \\
\text { (Kaninchen) }\end{array}$ & $\begin{array}{c}3= \\
9,3 \%\end{array}$ & $\begin{array}{l}\text { Plättchenthromben mit wenig } \\
\text { Leukozyten. Klein oval, } \\
\text { länglich gestaltet. Keine } \\
\text { Kokken, kein Fibrin. Der } \\
\text { eine hängt nicht mit der } \\
\text { Intimafläche zusammen. }\end{array}$ \\
\hline 2 & 40 & $\begin{array}{l}24 \mathrm{bis} \\
120 \mathrm{Std} .\end{array}$ & $\begin{array}{l}\text { Staphyl. } \\
\text { pyog. alb. }\end{array}$ & $\begin{array}{l}\text { Halsvenen } \\
\text { (Kaninchen) }\end{array}$ & $\begin{array}{c}8= \\
20 \%\end{array}$ & $\begin{array}{l}6 \text { Plättchenthromben, } 1 \text { Leu- } \\
\text { kozytenthrombus, 1 ge- } \\
\text { mischter Thrombus, die } \\
\text { Plättchenthromben sind } \\
\text { meist klein, oval oder oval- } \\
\text { länglich oder unregelmäßig } \\
\text { gestaltet, wenig Leuko- } \\
\text { zyten an sich; keine Kok- } \\
\text { ken; kein Fibrin auf Ober- } \\
\text { fläche. }\end{array}$ \\
\hline 3 & 10 & $\begin{array}{l}24 \mathrm{bis} \\
120 \mathrm{Std} .\end{array}$ & $\begin{array}{l}\text { Staphyl. } \\
\text { pyog. alb. }\end{array}$ & $\begin{array}{l}\text { Halsvenen } \\
\text { (Hund) }\end{array}$ & $\begin{array}{l}5= \\
50 \%\end{array}$ & $\begin{array}{l}\text { Plättchenthromben mit wenig } \\
\text { Leukozyten, klein, unregel- } \\
\text { mäBig gestaltet, zwei sind } \\
\text { fadenförmig gebaut. Zwei } \\
\text { hängen nicht mit der In- } \\
\text { timafläche zusammen. }\end{array}$ \\
\hline 4 & 18 & $\begin{array}{l}24 \mathrm{bis} \\
120 \mathrm{Std} .\end{array}$ & $\begin{array}{l}\text { Staphyl. } \\
\text { pyog. alb. }\end{array}$ & $\begin{array}{l}\text { Hals- und } \\
\text { Schenkel- } \\
\text { arterien } \\
\text { (Kaninchen } \\
\text { und Hund) }\end{array}$ & $\begin{array}{c}8= \\
44,4 \%\end{array}$ & $\begin{array}{l}5 \text { Plättchenthromben, } 3 \text { Leu- } \\
\text { kozytenthromben, klein, } \\
\text { oval oder länglichoval oder } \\
\text { halbkugelig, meist an der } \\
\text { Intimafläche festsitzend. } \\
\text { DiePlättchenthromben sind } \\
\text { teils ohne Leukozyten, teils } \\
\text { wenig am Rande sitzend. } \\
\text { Keine Kokken, kein Fibrin. }\end{array}$ \\
\hline 5 & 8 & $\begin{array}{l}24 \text { bis } \\
120 \text { Std. }\end{array}$ & $\begin{array}{l}\text { Pneumo- } \\
\text { kokken in } \\
\text { Bouillon }\end{array}$ & $\begin{array}{c}\text { Halsvenen } \\
\text { (Kaninchen) }\end{array}$ & $\begin{array}{r}2= \\
25 \%\end{array}$ & $\begin{array}{l}\text { Plättchenthromben klein, un- } \\
\text { regelmäßig oder fadenför- } \\
\text { mig gestaltet, wenig Leuko- } \\
\text { zyten am Rand. An der } \\
\text { Intima keine Kokken, keine } \\
\text { Fibrin. }\end{array}$ \\
\hline
\end{tabular}

der Arterie, die verhältnismäßig größere Thromben aufwiesen, so daß dieselben etwa die Hälfte des ganzen Querschnittlumens eingenommen hatten. Obliterierende Thromben haben wir im Gegensatze zu T alke nicht beobachtet.

Was die Form der Thromben angeht, so sind sie meist ovallänglich oder unregelmäßig. Wenn sich die Thromben direkt an der Intimafläche ansetzen, dann erscheinen sie mehr halbkugelig oder pilzförmig. Die Leukozytenthromben sind im allgemeinen unregelmäßig gestaltet und ihre Oberfläche ist gerieft. Wenn die 
Thromben nicht mit der Intimafläche im Zusammenhang stehen. dann sind sie mehr ovalrundlich oder etwas länglich.

Über die feinere Struktur der Plättchenthromben ist nicht viel anzugeben. Der Plättchenthrombus sieht nur mattweißlich körnig aus, an seinem Rande befinden sich, wie das Z urh ell e beschrieb, meist Leukozytenniederschläge, aber bisweilen auch im Innern der homogenen Thrombenbalken. Die Leukozyten zeigen keine deutlichen regressiven Veränderungen. Wem die Leukozyten am Rande der Thromben sitzen, dann stellen sie meist eine einfache Reihe dar.

Daß die Blutplättchen die wichtigsten Bestandteile der weißen menschlichen Thromben sind, wurde von $\mathrm{Os} l \mathrm{er}, \mathrm{Hayem}, \mathrm{Bizz}$ zero, $\mathrm{Hanau}$, Lubnitzki und von vielen andern behauptet. Es wird gesagt, daß äußerst selten reine Plättchenthromben im menschlichen Organismus vorkommen. Zurzeit stimmen manche Autoren darin überein, daß die Lenkozyten und Erythrozyten sich erst sekundär an den Plättchenthromben niederschlagen. Die Meinung scheint mir richtig. In meinen Untersuchungen habe ich auch häufig gefunden, daß die Plättchenthromben je nach der Länge der Versuchsdauer Leukozyten bald weniger, bald mehr aufweisen. In einem Präparat aus 5 tägiger Versuchsdauer der Arterie (Nr. 7) bildeten sich zwei große Thromben aus, der eine bestand nur aus Plättchen, der andere hauptsächlich aus Leukozyten; sonst habe ich häufig gesehen, daß die frischeren Plättchenthromben im allgemeinen weniger Leukozyten an sich besitzen als die älteren. Letztere scheinen sich etwas langsamer gebildet zu haben als erstere. Daher glaube ich, daßß zuerst ein Plättchenthrombus entsteht, dann durch das weitere Niederschlagen der sonstigen Blutelemente, sogenannte Leukozytenthromben und gemischte Thromben entstehen können. Fibrin wurde in unseren Fällen niemals nachgewiesen. Eberth und Sehim$\mathrm{melbuseh}$ und Weleh sind der Meinung gewesen, daß die Fibrinbildung mit Sicherheit als etwas Sekundäres bei der Thrombenbildung im strömenden Blut zu betrachten sei, wie auch As ch of f behauptet. In dieser Auffassung stimme ich mit den genannten Autoren überein.

In den Blutlakunen zwisehen den Thrombenbälkchen zeigten sich die Blutelemente fast immer normal. Die Erythrozyten blieben meistens unverändert, nur in einzelnen Fällen zeigten wenige Erythrozyten leichte Veränderungen. Weiße Blutkörperchen wiesen nirgends nennenswerte Veränderung auf. Kerne und Granula des Zelleibes sind stets gut erhalten. Nur in 2 oder 3 Fällen waren die Leukozyten gruppenweise angehäuft.

Es soll hier noch kurz über die Kokkenuntersuchung gesprochen werden. Schon längst ist uns bekannt, daß in der Wand bei Thrombophlebitis und in den Thromben zahlreiche pathogene Mikroorganismen nachgewiesen sind. Nach W e $1 \mathrm{eh}$ und $\mathrm{L} u \mathbf{b}$ a r s c h finden sich die aus der Wand eingewanderten Bakterien meist in späteren Stadien in bemerkenswerter Zahl. Wie $\mathrm{Zurhelle}$ richtig bemerkt, ist der positive Befund meistens kein Beweis dafür, daß die Bak- 
terien von Anfang an vorhanden waren und die Thrombose veranlaßten. T a l k e hat in seinen Experimenten 43 Fälle von Thrombosen untersucht, darunter waren 15 mal die Kokken vorhanden, während die andern 18 frei davon waren. Er sagte auch, daß sich in den älteren Thromben die Kokken häufiger fänden als in den frischen. Trotz des positiven Kokkenbefundes nahm er an, daß dieselben keinen direkten Einfluß auf die Thrombenbildung ausübten.

In meinen 108 Versuchen entstanden 28 mal Thromben. Ob nun die Thromben entstanden waren oder nicht, die positiven Kokkenbefunde im Gefäßlumen sind insgesamt nur $6(15,5 \%$ aus 2, 6, 8, 18, 20 und 48 Versuchsstunden an den Bauchvenen), und zwar sind die Kokken fast immer ganz spärlich nachzuweisen. Ferner in 2 Fällen (48 Stunden Versuchsdaner) wurden sie auch recht spärlich nur in der Intima nachgewiesen. In der Media wurden sie 5 mal aufgefunden. Es sei aber bemerkt, daß derartige negative Fälle dadurch bedingt sein können, daßs man gerade die betreffenden Stellen nicht untersuchte, in welchen Kokken vorhanden waren. Ferner muß man daran denken, daß die Kokken nicht so schnell durch die Gefäßwand durchtreten. Nach meinen Untersuchungen von $1 / 2$ bis 120 Stunden Versuchsdauer möchte ich bemerken, daß bei Kaninchen und Hunden die Kokken nicht so leicht durch die Wand dringen und im Lumen erscheinen. Wenn die Kokken an der Gefäßwand deponiert wurden, so fand nach 2 Stunden deutliche Emigration statt, nach weiteren Stunden sammelten sich in der Adventitia reichliche Leukozyten an. Durch diese lebhafte Reaktion des Organismus und die Dichtigkeit der Gefäßwand muß das weitere Eindringen der Mikroorganismen gehemmt werden, daher marschieren die Kokken auf den andern widerstandsärmeren Wegen, nämlich in dem lockeren Gewebe um die Gefäßwand herum und dringen weiter hinein. Ich habe in einem Falle von 5 Tagen Versuchsdauer bemerkt, daß die Kokken weder in der Media noch in der Intima der Seite des Experimentes gesehen wurden, sich aber in der gegenüberliegenden Adventitia reichlich befanden. Auf Grund dieser Beobachtung glaube ich, daß die Kokken die Gefäßwand nicht so leicht passieren können. Wenn sie in meinen Fällen in verhältnismäßig frühen Stadien im Lumen nachgewiesen wurden, so ist es doch nicht immer der Fall. Die Kokken waren in meinen Versuchsdauern meistens im Lumen negativ. Sicher ist, daß das Eindringen der Kokken noch in späteren Stadien vorkommt. Auch aus diesem Grunde glaube ich, daß die Kokken zur Thrombenbildung nicht in direkter Beziehung stehen, sondern sich wahrscheinlich sekundär in den Thromben ansiedeln.

Schließlich möchte ich hier kurz über die Entstehungsbedingungen der Thromben sprechen. Über die Bedingung der Thrombenbildung sind wir noch nicht ausreichend unterrichtet. Wir wissen zwar, daß weder eine Infektion noch eine besondere Gerinnungsfähigkeit des Blutes für das Zustandekommen der Thromben notwendig ist; wir wissen ferner, daß sie in erster Linie durch eine Abscheidung von Plättehen, denen die andern Bestandteile folgen, auf der Gefäßwand zustande 
kommt, aber es sind Meinungsverschiedenheiten darüber, ob für diese Abscheidung eine Veränderung der Gefäße maßgebend ist oder ob einer Verlangsamung der Blutbewegung mit gewissen Änderungen der Strömung die wichtigste Rolle zufällt. Der Hauptverteidiger der letzten mechanischen Theorie ist A s e h of f ${ }^{27}$, wie ich schon erwähnt habe. A s ch off und $L$ u bars $\mathrm{ch}$ stimmen darin überein, daß das Zustandekommen von Blutplättchen nur durch Verlangsamung der Blutströmung hervorgerufen werden kann.

In diesem Umstande haben die Autoren auch die Hauptbedingung für das Zustandekommen der Thromben gesehen. Zurhelle sagt, die Plättchenthromben entstehen rein mechanisch in dem stark verlangsamten Blutstrom. Die Elemente, die normalerweise sich in der Gefäßachse befinden, bleiben an der geschädigten Wandstelle haften, ballen sich dort zusammen und bilden so die Grundlage der sogenannten weißen Thromben. Kus a m a erklärte die Entstehungsbedingung in seiner Arbeit über toxische Thrombose in der Weise, daß erstens die erhöhte Agglutinierbarkeit, welche bei hämolysierenden Giften, hauptsächlich durch die bei der Hämolyse frei gewordenen thermolabilen Substanzen, die sich in den Blutschatten in der. Hämoglobinlösung finden, zweitens auch die primäre agglutinierende Wirkung der Gifte für die Thrombose in Betracht kommt. Zweitens ist langsame Zirkulation als wichtige Bedingung anzusehen, und drittens Endothelschädigung.

In Gegensatz zu derartigen Auffassungen stellt sich Ribbert. Er ist grundsätzlich der Meinung, daß die erste hauptsächlichste Bedingung für Thrombenbildung die Gefäßwandschädigung ist, und daß man es zunächst mit Veränderung der Gefäßwand zu tun hat, sei es, daß sie durch chronische Prozesse, wie Arteriosklerose, Phlebitis, Herde in der Herzwand oder durch eine rasch eintretende Schädigung, wie sie besonders oft in Betracht kommt, durch Infektion, durch eine Verletzung, ein Eindringen von Geschwulstzellen hervorgerufen wird. In weitaus den meisten Fällen aber verbindet sich damit eine Verlangsamung des Blutstromes, die primär für sich allein niemals ausreicht, die aber das Haften der sich auf der veränderten Wand abscheidenden Massen ermöglicht.

$\mathrm{R}$ i b b e r $\mathrm{t}^{14}$ prüfte das Fadenverfahren von $\mathrm{Z}$ u r h e $11 \mathrm{e}^{17}$ nach, es wurden Fäden quer durch die Venen gezogen. Dabei zeigte sich, daß die Blutplättchen sich nicht allein hinter den Fäden, wo nach A s c h of f walzenförmige Strömung zustande kommen soll, die natürlich mit Verlangsamung des Blutstromes einhergeht, sondern auch an der Vorderfläche niederschlagen, also dort, wo sich das Blut einfach teilt, um das Hindernis zu umfließen. Diese Beobachtung bestärkte seine Meinung noch mehr, daß irgendwelche besonderen Strömungen des Blutes für die erste Entstehung der Thrombose nicht maßgebend sein können. Wir glauben also, daß die Bedingung der Endothelschädigung bei den Versuchen der älteren Autoren nicht ohne weiteres auszuschließen ist, sie scheint vielmehr gerade bei den Ätzungsversuchen ( $Z$ a h n, Lö w i t, Eber th und Sch i m m elbusch, 
$\mathrm{Sch}$ a l be, Ribbert, Hanse n) eine besonders wichtige Rolle zu spielen, freilich nicht in dem Sinne, daß bei der Entblößung von Endothel die nackte Intima das Blut zur Gerinnung brächte, als vielmehr in der Richtung, daß dadurch das Anhaften der Blutplättchen begünstigt wird.

Wie dieses Anhaften zustande kommt, ist allerdings noch eine ungelöste Frage. Man muß jedenfalls zwei Störungen unterscheiden: eine akute und eine langsam eintretende Degeneration. In dem ersten Falle spielen die aus dem Gewebe austretenden Agglutinine und Koaguline, die hochgradigen Störungen der zwischen Gefäßwand und Blut stattfindenden Austauschvorgänge, die physikalische Rauhigkeit eine wichtige, aber bisher unberechenbare Rolle.

Es sei nur auf die entzündlichen Klappenthromben des Herzens hingewiesen, wieweit bei diesen degenerative Vorgänge und einfache Rauhigkeiten, soweit sie überhaupt entstehen, wieweit etwaige Fibringallerte im Sinne $L$ a k e r s ${ }^{50}$ eine Anhäufung der Plättchen bedingende Rolle spielen, ist um so weniger klar, als die degenerativen Vorgänge in ihren Beziehungen zur Thrombose, trotz Rib berts so warmem Eintreten für dieselben, bisher nicht einwandfrei nachgewiesen worden sind, ebensowenig wie die Fibringallerte L a k e $\mathrm{s}$, auf die Kle $\mathrm{mensiewicz}$ und $\mathrm{Gutsch} \mathrm{y}^{51}$ wieder neuerdings hingewiesen haben. $\mathrm{Ku}$ $\mathrm{s}$ a $\mathrm{ma}^{18}$ sagt: Da ohne nachweisbare Wandschädigung Thrombose nicht zu erzielen ist, sind die diesbezüglichen Verhälțnisse beim Menschen so schwer zu überschauen, um so mehr, als die frühesten Stadien der Thrombose so gut wie niemals zur Beobachtung gelangen können. Er hebt hervor, daß mit zahlreichen Mitteln ausgedehnte Plättchenthromben in strömendem Blute erzielt werden können, ohne daß irgendwelche lokale Endothelschädigung nachzuweisen ist. Damit sprach er sich gegen die von $R$ i b b e r t vertretene Anschauung aus, daß die Endothelschädigung oder Wandveränderung der ausschlaggebende Faktor bei der Thrombose ist. Nachdrüeklich hebt er hervor: „Es gibt typische Plättchenthromben, für deren Entstehung eine primäre Endothelschädigung in keiner Weise verantwortlich gemacht werden kann." Schließlich verteidigt er die A s c h o f f sche Theorie, wenn er sagt: „daß die Zustandsveränderung der Blutelemente und die Stromverlangsamung die für die Thrombose erst in Betracht kommenden Bedingungen sind". H a n s e $\mathrm{n}$ mit seinen reichlichen Ätzungsversuchen ist auch $\mathrm{R}$ i b b e r t s Meinung, daß die durch Ätzung hervorgerufene Gefäß $B$ wandnekrose (Intimanekrose) für die Thrombenbildung die wichtigste Rolle spielt. Nach meinen Untersuchungen zeigten die Gefäßwände in 28 positiven Fällen mit der typischen Thrombenbildung fast immer mehr oder weniger Endothelschädigung (Endothelnekrose oder Wucherung), durch welche die Glätte der Gefäßinnenwand verloren ging, wodurch Rauhigkeit und Unebenheit der Intimafläche entstand. Diese Intimanekrose ist nicht immer ausgedehnt, in wenigen Fällen hat sie geringen Umfang und entspricht der Intimastelle, welche gerade der. Stelle des Kokkendepots anliegt. In zwei Fällen habe ich aber ganz ausgedehnte Nekrose des ganzen Intimaumfanges 
gesehen, die eine ist von einer Vene bei dreitägiger Versuchsdauer und die andere von einer Arterie bei fünftägiger Versuchsdauer. Auf dieser uneben geschädigten Intimafläche schlagen sich die präexistierenden Blutplättchen nieder, die Masse vergrößert sich und bildet die Grundlage der weiteren Thrombose. Die Frage, ob Stromveränderung (Wirbelbewegung) an der Stelle der unebenen nekrotischen Intima mehr oder weniger auftrete, könnte vielleicht bejaht werden. Aber diese Stromveränderung ist natürlich in diesem Falle sekundär, sie kann also nicht als erste Bedingung zur Thrombenbildung aufgefaßt werden. Wir sehen doch auch keine Thrombenbildung, wo im intakten Organismus, im Herzohrinnern hinter. der Herzklappentasche der Aorta und Pulmonalis und hinter den Venenklappen mehr oder weniger Stromveränderung entstehen und daraus folgend Blutverlangsamung entstehen muß. B a u m gartens Versuch lehrt uns, daß Blutstillstand allein keine Blutgerinnung bedingt; $\mathrm{H}$ an se n kam zu demselben Ergebnis. Daher glaube ich, daß Stromverlangsamung allein nicht imstande ist, Thrombenbildung hervorzubringen, also keine erste Bedingung dafür ist.

Ich glaube also, daß wir uns der Ribbertschen Meinung anschließen müssen, daß die Gefäßwandschädigung die erste und wichtigste Bedingung für die Entstehung der Thromben ist; natürlich soll damit nicht gesagt sein; daß die Stromveränderung keine Rolle spielt, sie wird vielmehr in den meisten Fällen als ein wichtigse Moment hinzukommen.

\section{Schlubsätze.}

1. Es ist möglich, durch Infektion allein, ohne andere ursächliche Momente, eine Thrombose in dem Gefäß zu erzielen.

2. Dadurch entstandene Thromben sind in der Mehrzahl der Fälle aus Blutplättchen zusammengesetzt. Der Blutplättchenthrombus ist dabei eine Grundlage, ein Kern für weitere Thromben.

3. Bei derartigen Thrombosen üben die Mikroorganismen keinen di e k t e n Einfluß aus.

4. Die wichtigste Bedingung für die Thrombose ist die Gefäßwandschädigung; die Stromverlangsamung ist eine sekundäre, unterstützende Bedingung.

\section{Literatur.}

1. V ir c h ow, Handb. d. spez. Pathol. u. Ther. Bd. 1, 1854. - 2. B i z z o z z e r o, Über einen neuen Formbestandteil des Blutes und dessen Rolle bei der 'Thrombose und der Blutgerinnung. Virch. Arch. Bd. 90, 1882. - 3. H a n a u, Zur Entstehung und Zusammensetzung der Thrombose. Fortschr. d. Med. Bd. 4, 1886. - 4. L öw it, Über die Beziehnng der weißen Blutkörperchen zur Blutgerinnung. Ziegl. Beitr. Bd. 5. - 5. A r n o ld, Das Vorkommen und die Bedeutung der freien Kugelthromben im Herzen. Ziegl. Beitr. Bd. 8. - 6. C. J. E b e r th und $\mathrm{C}$. S c hi m m el b a s e h, Die Thrombose nach Versuehen und Leichenbefunden. Stuttgart 1888. - 7. Z a h n, Untersuehungen über Thrombose. Virch. Arch. Bd. 62, 1875. - 8. B r ü c k e, Ursache der Blutgerinnung. Virch. Arch. Bd. 17, 1875. - 9. C o h n h e i m, Vorlesungen über allgemeine Pathologie. 2. Aufl., 1882. - 10. B a u mg arte n, Über die Schicksale des Blutes in doppelt unterbundenen GefäBstrecken, Verhandlungen der D. Pathol. Ges. Bd. 5, 1902. - 11. Recklingh a usen, Handb. d. allg. Pathol. des Kreislaufes und der Ernährung. Stuttgart 
1883. - 12. As ch off, Über den Aufbau menschlicher Thrombose. Virch. Arch. Bd. 130; 1892. - 13. D e r s e ! b e , Über den Aufbau des Thrombus. Sitz. d. naturforsch. Ges., Freiburg, 20. Januar 1909. D. med. Wschr. Jg. 35, Nr. 8. - 14. R i b b e r t, Mehrere Artikel in D. med. Wschr. 1912-1913. - 15. K r e t z, Med. Klin. Bd. 41, 1909. - 16. A s e h of f, Med. Klin. Bd. 41, 1909. - 17. Z u r h elle, Experimentelle Untersuchungen über die Beziehung der Infektion und der Fibringerinnung zur Thrombenbildung im strömenden Blut. Ziegl. Beitr. Bd. 10, 57, S. 540, 1910. - 18. K u s a m a , Über den Aufban und Entstehung der toxischen Thrombose und deren Bedeutung. Ziegl. Beitr. Bd. 55, H. 3, 1913. - 19. Fr r ä n k e l, A., Über postoperative Thrombenbildung. Arch. f. klin. Chir. Bd, 86, 1908. - 20. M e n d e 1, Münch. med. Wschr. 1909, Nr. 42. - 21. F r o m m e, J., Ztlbl. f. Gyn. Nr. 1, 1909. - 22. B u m m , D. Ztschr. f. Geburtshilfe u. Gynäkol. Bd. 59, 1907. — 23. S i n g e r, Arch. f. Gynäkol. Bd. 56, S. 219, 1898. 24. S c h a u ta, Ansgewählte Kapitel der Geburtshilfe und Gynäkologie 1911. — 25. R e m m er, Ätiologie und Entstehung der postoperativen Thrombose und Embolie. Inang.-Diss., Freiburg 1909. - 26. Th o r e l, Lubarsch-Ostertags Ergebn. 1903, IX. 1., 1907 XI. 2., 1910. 27. M e r i e 1, Gaz. des hôp. 1908 S. 41-43. - 28. D u n c a n und Illm a n n, New York and Philad. med. Journ. 1907, Dez. -29 . We r t h e i m, Ztlbl. f. Pathol. Bd. 7, S. 37, 1896. 30. M o o re, A case of arterial thrombosis of gonorrhocal origin. Lancet, Dez. 19, 1903. 31. Ri e d e 1, D. med. Wschr. Nr. 21, S. 1258, 1911. - 32. S u t t o n, Thrombose und Embolie nach Operationen. Münch. med. Wschr. Nr. 14, S. 730, 1909. - 33. L e n a n d e r, Ztlbl. f: Chir. Nr. 19, 1899. - 34. Cornil, Bull. soc. anat. 10. Dez. 1884. - 35. W i d a l, Thése de Paris 1889; zit. nach V a g u ez. - 36. V a g u e $z$, De la thromb. cachectique. Thèse de Paris 1890. - 37. L a b a s c h, Handb. d. allg. Pathol. Wiesbaden. Bd. 1, 1905. — 38. v. B a r d el e ben, Streptococeus und Thrombose. Arch. f. Gynäkol. Bd. 83, H. 1, 1907. - 39 . J a k ow s k y, Beiträge zur Kenntnis der Venenthrombose infektiösen Ursprungs. Ztlbl. $f$. Bakt. u. Parasit. Bd. 25, 1898. - 40. L o e b. The influence of certain bacteria on the coagulation of the blood. Journ. of medical research. vol. X, nr. 3, p. 407, 1903. - 41. W e $1 \mathrm{ch}, \mathrm{W}$. H., Thrombosis and Embolie. Albutt's system of medicine 1904. - 42. D e r s e 1 b e , The structure of white thrombi, Transaction of the pathological society of Philadelphia Bd. 13, 1887. - 43. Fro m m e, J., Experimentelles zur Entstehung der Thrombose. Verhandlung der Ges. deutsch. Naturforsch. u. Ärzte, 2. Teil, 2. Hälfte, S. 292, 1909. - 44. Cr o c q : Contribution à l'étude expérimentale des artérites infectienses. Arch. de méd. 1894, no. 4. - 45. R i b b e r t, Beiträge zur normalen und pathologischen Anatomie und Physiologie der Niere. Bibl. med. 1908. 46. Freudweiler, Über experimentelle Phlebitis. Virch. Arch. Bd. 141, H. 3, S. 526, 1895. - 47. Y a ts us hir o, Experimentelle Stidie über die Emigration von Leukozyten bei der Entzündung. Frankf. Zeitschr. f. Pathol. Nr. 12, 1912. - 48. T a l k e Experimenteller Beitrag zur Kenntnis der infektiösen Thrombose. Beiträge z. klin. Chir. Bd. 36, H. 2, S. 339, 1902. - 49. Ha $\mathrm{s}$ e n, Zur Frage der Thrombose. Virch. Arch. Bd. 213, H. 1, S. 65. - 50. L a k e r, Die erste Gerinnungserscheinung des Säugetierblutes unter dem Mikroskop. Sitzungsber. d. Kais. Akademie d. Wiss., Wien, 3. Abt., 1884. - 51. K l e me n s i e w i c z und G u t s e h y, Zur Morphologie der Blutgerinnung und der Thrombose. Ziegl. Beitr. Bd. 34, 1903.

\section{XIX.}

\section{Die Gestalt der Gefäßlichtung bei der diffusen und knoti- gen Arteriosklerose.}

Von

Prof. R. T h o m a in Heidelberg.

Die allgemeinen Gesichtspunkte, welche sich bei der Untersuchung sklerotischer Arterien ergeben, habe ich ${ }^{1}$ ) vor einigen Jahren zusammenzufassen versucht.

1) R. Thoma, Über die Histomechanik des GefäßBsystems und die Pathogenese der Angiosklerose. Virch. Arch. Bd. 204, 1911. In dieser Abhandlung finden sich auch die hier nicht besonders genannten Arbeiten zitiert. 